UNIVERSIDADE DE SÃO PAULO

ESCOLA DE ENGENHARIA DE SÃO CARLOS

DEPARTAMENTO DE ENGENHARIA DE ESTRUTURAS

DAVID DE PAULO PEREIRA

ANÁLISE NÃO LINEAR GEOMÉTRICA DE SÓLIDOS ELÁSTICOS TRIDIMENSIONAIS REFORÇADOS COM FIBRAS ATRAVÉS DO MÉTODO DOS ELEMENTOS FINITOS 



\title{
ANÁLISE NÃO LINEAR GEOMÉTRICA DE SÓLIDOS ELÁSTICOS TRIDIMENSIONAIS REFORÇADOS COM FIBRAS ATRAVÉS DO MÉTODO DOS ELEMENTOS FINITOS
}

\author{
VERSÃO CORRIGIDA \\ A versão original encontra-se na Escola de Engenharia de São Carlos
}

Dissertação apresentada ao Departamento de Engenharia de Estruturas da Escola de Engenharia de São Carlos, Universidade de São Paulo, como parte dos requisitos para obtenção do título de Mestre em Engenharia Civil (Estruturas).

Orientador: Prof. Dr. Rodrigo Ribeiro Paccola

São Carlos 
AUTORIZO A REPRODUÇÃO TOTAL OU PARCIAL DESTE TRABALHO POR QUALQUER MEIO CONVENCIONAL OU ELETRÔNICO, PARA FINS DE ESTUDO E PESQUISA, DESDE QUE CITADA A FONTE.

Pereira, David de Paulo

Análise não linear geométrica de sólidos elásticos tridimensionais reforçados com fibras através do método dos elementos finitos / David de Paulo Pereira; orientador Rodrigo Ribeiro Paccola. São Carlos, 2015.

Dissertação (Mestrado) - Programa de Pós-Graduação em Engenharia de Estruturas -- Escola de Engenharia de São Carlos da Universidade de São Paulo, 2015.

1. Elemento Finito Posicional. 2. Materiais Compósitos. 3. Análise Não Linear de Estruturas. 4. Sólidos reforçados com fibras. 5. Fibras aleatórias. I. Título. 


\section{FOLHA DE JULGAMENTO}

Candidato: Engenheiro DAVID DE PAULO PEREIRA.

Título da dissertação: "Análise não linear geométrica de sólidos elásticos tridimensionais reforçados com fibras através do método dos elementos finitos".

Data da defesa: 14/12/2015

\section{Comissão Julgadora:}

Prof. Dr. Rodrigo Ribeiro Paccola (Orientador)

(Escola de Engenharia de São Carlos/EESC)

Prof. Titular Humberto Breves Coda

(Escola de Engenharia de São Carlos/EESC)

Prof. Dr. Rodrigo Bresciani Canto

(Universidade Federal de São Carlos/UFSCar)

\section{Resultado:}

Aprovaso

Airuuado

APROVADO

Coordenador do Programa de Pós-Graduação em Engenheira Civil (Engenharia de Estruturas):

Prof. Titular Humberto Breves Coda

Presidente da Comissão de Pós-Graduação:

Prof. Associado Paulo Sergio Lima Segantine 

Para os meus familiares Patricia, Nilda, Vicente, Priscila, João e Denis. 



\section{AGRADECIMENTOS}

Ao meu orientador, professor Rodrigo Ribeiro Paccola, pela amizade criada, por toda dedicação e paciência durante a orientação, e por seus ensinamentos constantes.

Ao professor. Humberto Breves Coda, por toda a sua contribuição à pesquisa e por seus conselhos.

Aos meus pais, por terem me dado todo o apoio necessário para a concretização desta pesquisa.

Ao Departamento de Engenharia de Estruturas da Escola de Engenharia de São Carlos da Universidade de São Paulo (SET/EESC/USP) pela disponibilização das instalações e recursos computacionais para o desenvolvimento desta pesquisa.

A todos que, diretamente e indiretamente, contribuíram para este trabalho.

A Deus que sempre está comigo. 

"Ninguém chegou a ser sábio por acaso." Seneca 



\section{RESUMO}

PEREIRA, D. de P. Análise não linear geométrica de sólidos elásticos tridimensionais reforçados com fibras através do método dos elementos finitos. 2015. 85 p. Dissertação (Mestrado em Engenharia de Estruturas) - Departamento de Engenharia de Estruturas, Escola de Engenharia de São Carlos, Universidade de São Paulo, São Carlos, 2015.

O presente trabalho tem por finalidade estudar e implementar um modelo numérico de análises cinemáticas de sólidos tridimensionais via método dos elementos finitos posicionais, com consideração de fibras longas ou curtas inseridas de maneira aleatória ou não no domínio da análise. O modelo numérico considera material isotrópico para a matriz e não linearidade geométrica. O domínio do sólido é discretizado por meio de elementos finitos tetraédricos de ordem qualquer, cujos parâmetros nodais são suas posições. A medida de deformação utilizada é a de Green, associada à lei constitutiva de Saint-Venant-Kirchhoff, referenciada pela configuração inicial do corpo, caracterizando o sistema de espaço como Lagrangiano total. O cálculo da posição de equilíbrio é baseado no princípio da mínima energia potencial total. Para a resolução do problema não linear geométrico, adota-se o método iterativo de Newton-Raphson. A inserção das fibras no domínio da análise é feita com a associação das mesmas com elementos finitos unidimensionais curvos de ordem qualquer, cujas posições nodais são dadas em função das posições dos nós dos elementos de sólido. Essa abordagem tem como vantagem o fato de não aumentar o número de graus de liberdade do sistema, ao mesmo tempo em que não limita as posições das fibras dentro do domínio por não ser necessária a coincidência das malhas. Exemplos são apresentados para validação dos desenvolvimentos e implementações realizadas.

Palavras-chave: Elemento Finito Posicional. Materiais Compósitos. Análise Não Linear de Estruturas. Sólidos reforçados com fibras. Fibras aleatórias. 



\begin{abstract}
PEREIRA, D. de P. Geometric nonlinear analysis of fiber reinforced tridimensional elastic solids using finite element method. 2015. 85 p. Dissertation (M. Sc. In Structural Engineering) - Department of Structural Engineering, School of Engineering of São Carlos, University of São Paulo, São Carlos, 2015.
\end{abstract}

This study aims to develop and implement a numerical model of kinematic enrichment, to analyze tridimensional solids based on positional finite element method, considering long and short fibers random distributed inside the domain. The numerical model considers isotropic material and geometric nonlinear behavior for both matrix and fibers. Tetrahedral finite elements with any order of approximation are used to discretize the solid domain, with positions as nodal parameters. Green strain and Saint-Venant-Kirchhoff constitutive law are used, referenced in initial configuration of the body, characterizing the developed formulation as total Lagrangian. The equilibrium is obtained with the application of Total Potential Energy Principle, adopting the Newton-Raphson method to solve the resulting nonlinear system of equations. The fibers are considered in the formulation using curved onedimensional finite elements with any order of approximation, and the nodal positions of the fibers are related with the nodal positions of the solid elements. The coupling method adopted does not increase the number of degrees of freedom of the system, and does not limit the positions of the fiber nodes to be coincident with solid nodes. Examples are presented in order to validate the developed and implemented formulations.

Keywords: Positional Finite Element. Composite Materials. Nonlinear Structural Analysis. Fiber Reinforced Solids. Random Fibers. 



\section{SUMÁRIO}

1 INTRODUÇÃO 19

1.1 Considerações Iniciais 19

1.2 Materiais Compósitos 21

1.3 Motivação e Objetivos da Pesquisa 25

1.4 Organização da Dissertação 29

2 REVISÃO BIBLIOGRÁFICA

2.1 Evolução dos Estudos de Reforços com Fibras 31

2.2 Simulação Numérica de Compósitos Reforçados com Fibras 33

2.3 Elementos Finitos Posicional Aplicados em Compósitos Reforçados com 37 Fibras

3 ELEMENTO FINITO DE SÓLIDO TRIDIMENSIONAL REFORÇADO POR 39 FIBRAS

3.1 Problemas Elásticos Tridimensionais 39

3.2 Cinemática para o Meio Contínuo 42

3.2.1 Energia de Deformação 46

$\begin{array}{ll}\text { 3.2.2 Considerações para o Sólido } & 47\end{array}$

3.2.3 Considerações para as Fibras 48

3.2.4 Acoplamento Fibra - Sólido 52

4 EXEMPLOS DE APLICAÇÃO

4.1 Exemplo 1: Viga engastada submetida a carregamento concentrado 58

4.2 Exemplo 2: Flambagem elástica de Euler 61

4.3 Exemplo 3: Viga reforçada engastada submetida a carregamento distribuído $\quad 63$

4.4 Exemplo 4: Placa reforçada simplesmente apoiada 64

4.5 Exemplo 5: Viga reforçada com fibras curtas aleatórias 67

5 CONCLUSÕES

5.1 Considerações Finais $\quad 71$

$\begin{array}{ll}5.2 \text { Propostas de Trabalhos Futuros } & 72\end{array}$

REFERÊNCIAS BIBLIOGRÁFICAS 



\section{INTRODUÇÃO}

Neste capítulo são apresentadas considerações iniciais relacionadas ao tema, as motivações e os objetivos da pesquisa e, por fim, apresenta-se como foi organizada a dissertação na estrutura de capítulos.

\subsection{CONSIDERAÇÕES INICIAIS}

A ideia de se combinar dois materiais diferentes para obter um terceiro material com propriedades afins superiores é relativamente simples, visto que por volta de quatro mil anos atrás a antiga civilização egípcia já fazia uso de tijolos de barro reforçados com palha picada na construção de pequenas estruturas como casas ou armazéns (EXODO-5:7; MENDONÇA, 2005). Materiais como este são denominados compostos ou compósitos, e têm por definição a combinação de dois ou mais materiais de maneira multifásica (sob o ponto de vista macroscópico), a fim de dar origem a um novo material (multifásico) com propriedades mecânicas melhoradas, se comparadas às dos materiais que deram origem ao compósito (CALLISTER, 2005). A vantagem dos materiais compósitos em relação aos materiais homogêneos, é que as propriedades desejáveis de diferentes materiais podem ser aproveitadas no mesmo componente estrutural (PASCON, 2012).

Embora esta ideia seja antiga, de acordo com Riul (2009) a primeira patente de um compósito estrutural data de 1916, porém só na década de 40, durante a segunda guerra, o tema foi popularizado mundialmente, isto porque as estruturas das aeronaves até então eram baseadas em ligas metálicas, que sofriam com o peso e corrosão. A necessidade de aeronaves mais leves e resistentes à corrosão impulsionou as pesquisas para a obtenção de novos materiais que pudessem substituir os vergalhões de aço e outros componentes estruturais. Em 1949, com o advento da fibra de vidro, se deu início ao desenvolvimento dos compósitos modernos, e a partir daí gradativamente os compósitos estão substituindo 
as peças de ligas leves nas aeronaves. Hoje a estrutura de uma aeronave típica já possui uma parcela significativa de compósitos.

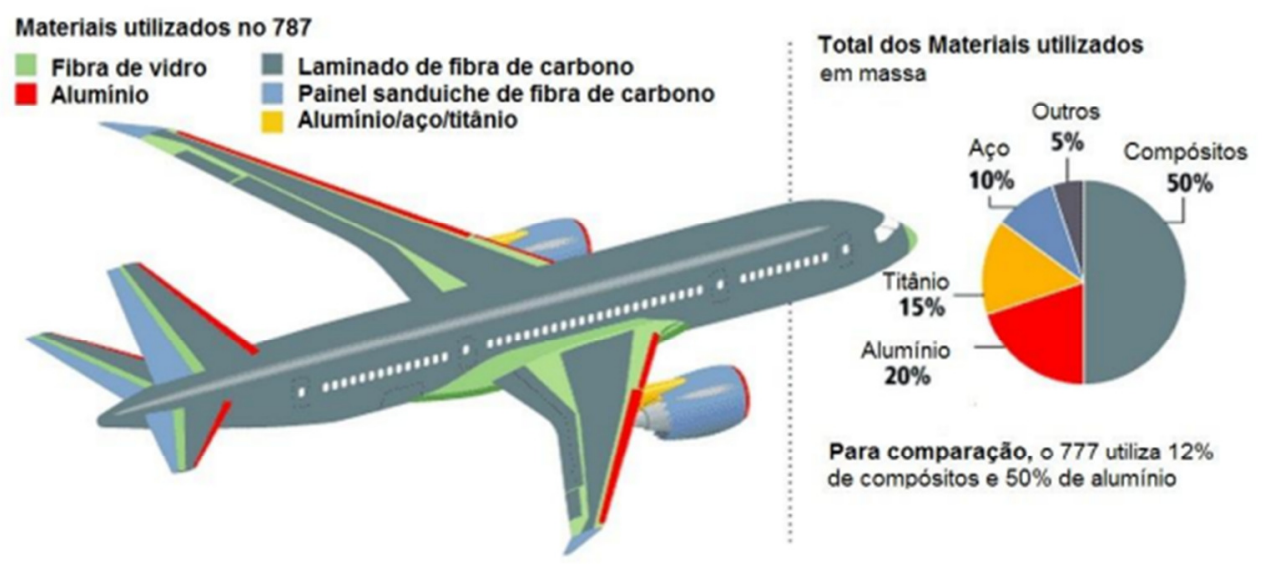

Figura 01 - Boeing 787. Fonte: Boeing.com

No desenvolvimento deste tipo de material se busca principalmente a melhoria de propriedades mecânicas como, por exemplo: rigidez, tenacidade e resistência às solicitações. Devido à grande possibilidade de combinações que pode dar origem a um compósito, este tipo de material deixou de ser exclusivo da indústria aeronáutica e passou a ser uma alternativa muito interessante para várias outras áreas da indústria como: automobilística, de eletroeletrônicos, de equipamentos esportivos, petroquímica, etc (GAY, 2003).

Na construção civil o uso de materiais compósitos já é bastante recorrente, como por exemplo, o concreto armado, que tem como principal vantagem o ganho de resistência à tração proporcionada pelo aço, estruturas mistas, protendidas, etc. Porém, com a necessidade de se projetar e construir estruturas cada vez mais arrojadas, novos compósitos passaram a ser considerados, e dos muitos tipos de compósitos se destaca o reforçado por fibras, objeto de estudo deste trabalho. 


\subsection{MATERIAIS COMPÓSITOS}

Material compósito é aquele criado após a combinação de dois ou mais constituintes, ou fases. A cada fase é dado um nome conforme seu desempenho na finalidade das propriedades do material final.

Em geral, um material compósito é constituído por uma fase denominada de matriz, componente contínuo, mas nem sempre em maior quantidade, de baixas propriedades mecânicas, mas de fácil moldagem, cujo objetivo é transmitir as solicitações para os materiais da fase de reforço e manter os mesmos ligados entre si; podendo a fase de reforço ser na forma de fibras, partículas ou lâminas, cuja finalidade é aprimorar uma ou mais propriedades mecânicas da matriz.

Por vezes ainda é considerada uma terceira fase distinta, localizada entre as fases matriz e reforço, e denominada interface ou zona de transição.

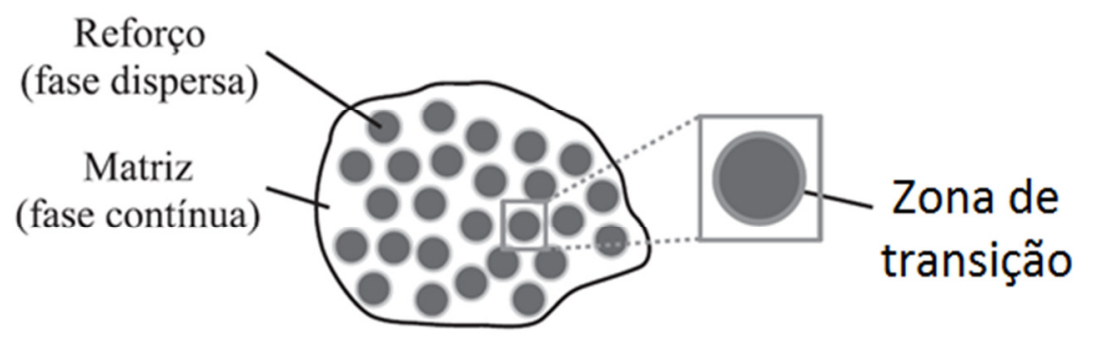

Figura 02 - Fases de um material compósito (DANIEL;ISHAI,2006)

Segundo Daniel e Ishai (2006) esta fase tem o papel de proporcionar a correta transmissão de esforços entre a matriz e o reforço, ou seja, para uma transmissão eficaz de esforços deve-se garantir uma boa adesão entre a matriz e o reforço, e por vezes é necessário um tratamento superficial no material reforçante. A formulação desenvolvida neste trabalho considera aderência perfeita entre as fases, em outras palavras, durante o processo de deformação a fibra não desliza em relação à matriz, não sendo, portanto, modelada a interface ou zona de transição.

Devido à grande variedade de materiais e inúmeras combinações que dão origem aos compósitos, surgiu a necessidade de classificá-los. Neste sentido, Mendonça (2005) classifica os materiais compósitos de acordo com as suas características geométricas que podem ser particulados, fibrosos ou laminados. Já Hull (1988) classifica os compósitos em 
dois grandes grupos, os naturais, que provém de combinações de materiais criados pela natureza e os sintéticos, que são fabricados pelo homem, portanto, de natureza artificial. Ainda segundo Hull (1988) os compósitos sintéticos podem ser subdivididos em macroscópico, materiais em que suas fases são macroscópicas, ou seja, podem ser distinguidas a olho nu, e os microscópios, materiais em que suas fases só podem ser distinguidas com o auxílio de microscopia.

Tabela 01 - Classificação dos materiais segundo seus constituintes (HULL, 1988).

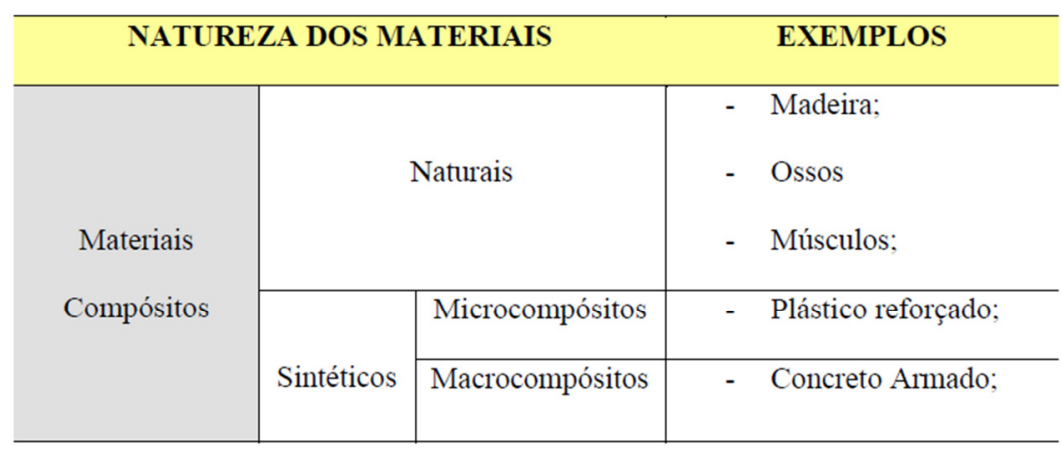

Os compósitos ainda podem ser classificados como reforçados com partículas, reforçados com fibras e híbridos (CALLISTER 2005), podendo ser subdivididos conforme apresentado na Figura 03.

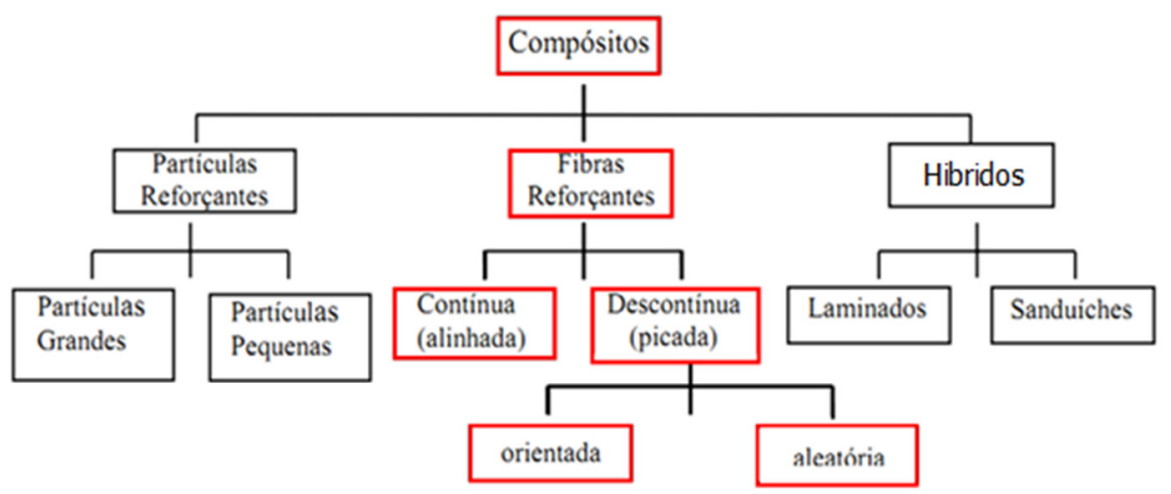

Figura 03 - Classificação dos materiais compósitos com destaque para fibras reforçantes

(ADAPTADO de CALLISTER 2005)

Callister (2005) define um compósito com partículas reforçantes, como aquele em que o material de reforço é equiaxial, ou seja, possui dimensões aproximadas em qualquer direção que se meça. Já o termo grande (Figura 03) se refere às partículas de um tamanho suficiente 
para que as interações matriz-reforço não possam ser tratadas em um nível atômico, ao invés disso, a mecânica do contínuo deve ser aplicada. Em geral, neste tipo de compósito a fase particulada é mais dura e mais rígida que a matriz, restringindo a movimentação da mesma em suas vizinhanças, já a matriz essencialmente transfere parte da tensão aplicada às partículas.

Para que em um compósito particulado o reforço seja eficaz, se deve obter uma disposição homogênea das partículas e que as mesmas sejam pequenas, “...pois quanto menor o volume de um material também é menor a chance do mesmo possuir algum defeito" (ROESLER et al., 2007). Um exemplo deste tipo de material é o concreto, composto de cimento (a matriz) e de areia e brita (os particulados), em que ambos os materiais, matriz e reforço são cerâmicos.

Ainda segundo Callister (2005), é considerado um compósito híbrido aquele que não depende somente das propriedades dos materiais, mas também do projeto geométrico dos vários elementos estruturais. Dentre os compósitos estruturais, os mais comuns são os laminados e os painéis sanduiche. Um compósito laminado é composto por lâminas ou painéis bidimensionais que possuem uma direção com alta resistência, sendo as lâminas empilhadas e unidas umas às outras de tal modo que a orientação da direção com alta resistência varie de uma camada para outra. Desse modo, um compósito laminado em qualquer direção do plano bidimensional possui uma resistência relativamente alta, no entanto, a resistência em qualquer direção é menor que no caso de todas as fibras estarem orientadas naquela direção (CALLISTER 2005). Os compósitos laminados podem ser planos em formas de placas ou curvos em formas de cascas (SAMPAIO, 2014).

Um compósito sanduiche é obtido por uma junção de duas camadas, ou lâminas, externas resistentes, separadas por um núcleo adesivo e mais leve, este núcleo fornece um aumento na espessura do conjunto, trazendo um ganho de rigidez ao mesmo tempo em que não aumenta consideravelmente o peso da estrutura (VALENTE, 2012). Este material geralmente é projetado como painéis e vigas de rigidez, com resistência relativamente elevadas e baixo peso (CALLISTEER, 2005).

Compósitos reforçados com fibras são aqueles em que o material de reforço se manifesta na forma de fibra. "Tecnologicamente os compósitos reforçados com fibras são os mais importantes.”(CALLISTEER, 2005), isso devido às inúmeras aplicações que este tipo de compósito tem nas várias áreas da indústria. 
Segundo Hyer e White (1998) uma fibra se forma seguindo a orientação preferencial das ligações atômicas e moleculares em sua direção longitudinal, o que promove às fibras melhores propriedades mecânicas naquela direção. Quando há mais de um tipo de fibra como material de reforço o compósito recebe o nome de misto (HYER e WHITE, 1998).

Pode-se definir como fibra, todo material reforçante que possui uma dimensão muito maior que as outras duas. A "American Society for Testing Materials - ASTM, Committee D30" define fibras como materiais alongados com a maior dimensão na razão de, pelo menos, 10/1, em comparação com as outras, com uma seção transversal de $5 \times 10^{-2} \mathrm{~mm}^{2}$ e espessura máxima de 0,25 mm (JUVANDES et al., 1996).

Já Callister (2005) define fibra, como um material de pequeno diâmetro e muito mais resistente que o mesmo material em dimensões volumétricas. Segundo Griffith (1921), as fibras apresentam propriedades muito superiores às dos materiais que as originaram na forma maciça, o referido autor também constatou que o vidro na forma maciça apresentava tensões de ruptura de cerca de $170 \mathrm{MPa}$, enquanto fibras de vidro com cerca de $20 \mu \mathrm{m}$ de diâmetro, chegavam a tensões de ruptura de $3500 \mathrm{MPa}$, tendo concluído que o uso de fibras é uma das principais razões para a grande melhoria nas características mecânicas dos compósitos. Como a fibra possui uma rigidez maior que o material volumétrico (matriz), fica claro que é esta quem suportará as cargas transferidas da matriz (TITA, 1999).

Com relação à distribuição, as fibras podem ser contínuas e alinhadas, descontínuas e alinhadas ou descontinuas e desalinhadas (CALLISTER, 2005). Conforme já foi dito, uma fibra possui propriedades mecânicas melhores na direção longitudinal, logo um compósito fibroso, com as fibras alinhadas, irá suportar carregamentos mais elevados quando os mesmos atuarem na direção das fibras. Todavia, as fibras dispostas numa direção normal ao carregamento atuante podem promover até mesmo redução na resistência do compósito (HULL, 1988; CALLISTER 2005).

As principais fibras utilizadas como reforços hoje em dia são: Fibra de vidro, Fibra de Carbono, Aramida (ou Kevlar), Fibra de Boro e Carbeto de Silício. (GAY, 2003; Juvandes et al., 1996).

Ainda se pode destacar as fibras de origem vegetais por trazerem outros tipos de vantagens, como financeira, e por se tratar de um recurso praticamente ilimitado e renovável, portanto sustentável do ponto de vista ambiental. Por exemplo, em se tratando de construção civil, tem-se que a mesma já utiliza compósitos reforçados por fibras naturais na construção de grades de proteção em pontes de rodovias (DWEIB et al., 2004). 


\subsection{MOTIVAÇÃO E OBJETIVOS DA PESQUISA}

Os compósitos reforçados com fibras atualmente representam uma grande parte de toda a exploração comercial de compósitos, pois como já mencionado, estes se tornaram uma alternativa interessante para diversas áreas da indústria. Isso porque reforços com fibras geralmente são fáceis de confeccionar e baratos, além de melhorar várias propriedades de diferentes tipos de matrizes, como, por exemplo, matrizes poliméricas, que quando reforçadas com fibras de carbono tendem a possuir uma tenacidade e resistência a diferentes tipos de solicitações mecânicas melhoradas, inclusive em diferentes temperaturas (CALLISTER 2005), tornando possível a aplicação deste tipo de compósito desde a fabricação de varas de pesca até partes específicas de uma aeronave.

Já matrizes frágeis (geralmente cerâmicas) quando reforçadas com fibras, melhoram consideravelmente as propriedades de tração e flexão, que no caso particular do cimento, significa uma alteração das propriedades reológicas da mistura fresca, um controle da fissuração do concreto e uma mudança do seu comportamento à fratura, conferindo maior capacidade de carregamento após o aparecimento das primeiras trincas (HANNANT, 1978). Com isso, o reforço com fibras passa também a ser interessante para diferentes elementos de uma estrutura de construção civil.

Portanto, pela grande aplicabilidade comercial, é estratégica a correta previsão do grau de solicitação máximo que um compósito reforçado com fibras pode suportar, ou seja, para a aplicação segura deste material, deve-se, de antemão, prever com certa eficiência quando e como a ruptura acontecerá. Tal previsão é essencial, para se obter com determinado grau de confiança e segurança o dimensionamento estrutural (PASCON, 2012). Em um compósito reforçado com fibras, a falha pode acontecer na matriz, na fibra, ou pelo deslocamento entre a fibra e a matriz (DANIEL; ISHAI 2006).

A previsão de falha é obtida principalmente de duas maneiras: uma empírica e experimental, que fornece por meio de ensaios, o grau de solicitação máximo que um determinado material pode suportar; e outra matemática, analítica para casos simples, ou numérica para casos mais gerais. Esta formulação é obtida principalmente durante a tentativa de entender o porquê da falha, e a partir daí prever falhas futuras por diferentes tipos de solicitações. A estas previsões se dá o nome de critérios de falhas, ou critério de resistência. 
Em geral, ensaios mecânicos são onerosos, tanto em termos financeiros, quanto no que concerne ao tempo. Portanto, os engenheiros, na tentativa de prever a falha de um material, têm recorrido aos métodos numéricos, com destaque ao Método dos Elementos Finitos, que quase sempre são aplicados com o auxílio de computadores. Isso pode ser visto, por exemplo, na indústria automobilística, a qual vem substituindo seus ensaios de impacto de carro com anteparo rígido por simulações computacionais. (PASCON, 2012).

Os mecanismos de falha de um material compósito variam bastante com suas propriedades e com o tipo de carregamento (COSTA et al., 2010), mas em geral para a determinação da falha de um material usando qualquer critério, deve-se conhecer o campo de tensões ou deformações do mesmo, ou seja, para a determinação da falha de um material, antes deve-se conhecer seu comportamento mecânico e a partir daí aplicar um critério de falha adequado.

Segundo Sampaio (2014), resolver o problema de comportamento mecânico consiste principalmente em se obter a posição de equilíbrio de uma estrutura, os campos de deslocamento, tensões e deformações. Em casos onde a estrutura sofre grandes deformações e deslocamentos, ou seja, a posição de equilíbrio da estrutura se afasta muito da posição inicial, a consideração da não linearidade geométrica nas formulações utilizadas se faz necessária.

Em se tratando de sólidos reforçados com fibras, várias formulações são propostas para a análise estrutural, algumas dessas são citadas no Capítulo 02. Estas formulações podem ser organizadas em pelo menos quatro grandes grupos: os modelos em que o meio compósito heterogêneo é substituído por um homogêneo equivalente; os modelos em que tanto a matriz quanto as fibras são discretizadas com elementos sólidos tridimensionais; os modelos em que a matriz é discretizada com elementos simplificados como chapas ou casca e as fibras com elementos de barra; e os modelos em que a rigidez das fibras é distribuída na rigidez do elemento finito de sólido (BARUT et al., 2000). Em geral, estes modelos ou dificultam a análise do problema de forma local ou aumentam consideravelmente o número de graus de liberdade (incógnitas) do sistema de equações resultante, e/ou exigem a coincidência dos nós da malha das fibras com os nós da malha da matriz na discretização do problema. (SAMPAIO, 2014).

Diante disso o objetivo principal deste trabalho é desenvolver uma formulação alternativa, com parâmetros posicionais, considerando a não-linearidade geométrica para análise do comportamento mecânico de sólidos tridimensionais reforçados com fibras. O meio contínuo é discretizado em elementos tetraédricos e as fibras em elementos de barras, 
podendo ou não ser curvas, sendo que para ambos permite-se adotar qualquer grau de aproximação para as variáveis envolvidas na análise. A fim de aliviar o custo computacional inerente à formulação tridimensional, as fibras são introduzidas no sistema de uma maneira em que não se aumente o número de graus de liberdade do problema.

Nos últimos anos, diversas formulações foram desenvolvidas e implementadas no grupo de pesquisa no qual se insere o presente trabalho, tanto relacionadas à análise não linear geométrica de barras e sólidos bidimensionais e tridimensionais, quanto à simulação do comportamento de compósitos particulados, laminados e reforçados por fibras (VANALLI, 2004; GRECO, 2004; CODA e GRECO, 2004; PACCOLA et al., 2008; CODA e PACCOLA, 2007, 2008; MACIEL, 2008, PASCON, 2012; SAMPAIO, 2014; MOURA, 2015; NOGUEIRA, 2015). Esses trabalhos, de uma forma geral, serviram de base para os desenvolvimentos aqui apresentados.

A metodologia adotada para se alcançar os objetivos propostos na presente pesquisa permitiu um gradual aprendizado dos conhecimentos aplicados, possibilitando um melhor entendimento da formulação em cada etapa desenvolvida, conforme apresentado a seguir:

- Formulação e implementação de elemento finito de barra simples (treliça), bidimensional e tridimensional, com consideração de não linearidade geométrica, usado posteriormente para simular trechos de fibras contínuas e/ou fibras curtas inseridas no contínuo, Figura 04;
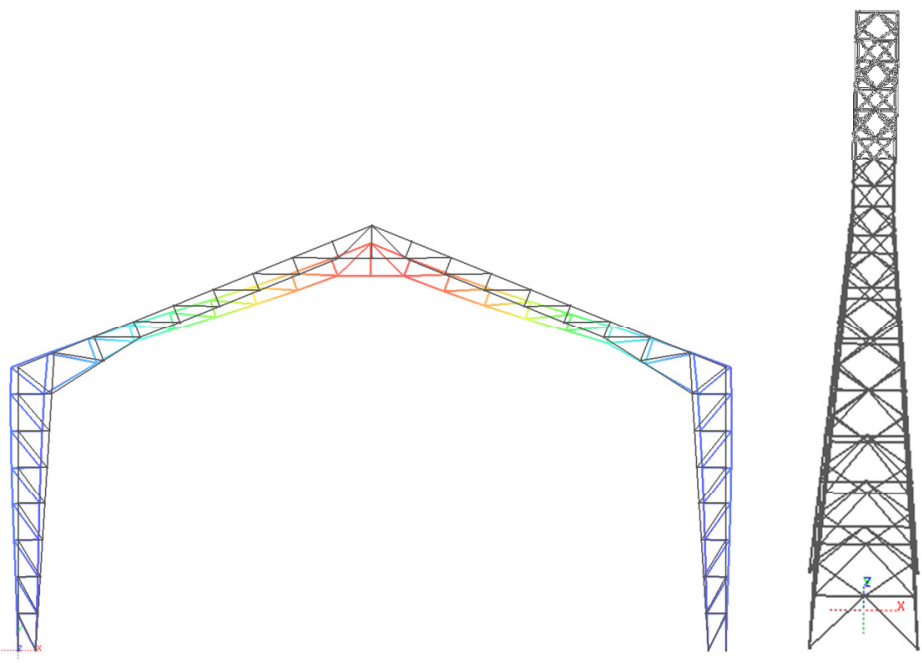

Figura 04-Elementos finitos de barra simples (2D /3D) 
- Formulação e implementação de elemento finito de chapa, com consideração de não linearidade geométrica e possibilidade de se adotar qualquer grau de aproximação para as variáveis nodais. Este código serviu de base para as implementações do elemento finito tridimensional, utilizado para simular o contínuo na presente pesquisa, Figura 05;

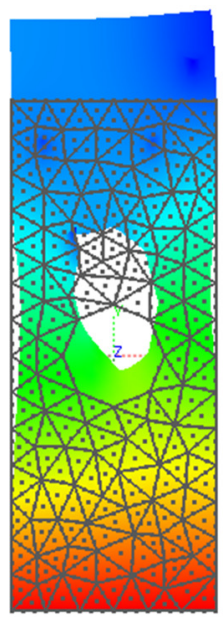

Figura 05- Elemento finito de chapa.

- Formulação de elemento finito tridimensional (tetraédrico), com qualquer grau de aproximação para as variáveis nodais e consideração de não linearidade geométrica, partindo da formulação do elemento de chapa mencionada no item anterior;

- Adaptação do código de treliça para consideração de diferentes graus de aproximação para o elemento de barra simples, permitindo a utilização de fibras retas e curvas;

- Implementação do acoplamento entre os elementos de sólido e de fibra, seguindo estratégia apresentada em Vanalli (2004) e Sampaio (2014), adaptando a ideia para chapas, placas e cascas utilizada pelos referidos autores para o caso tridimensional da presente pesquisa;

- Desenvolvimento de gerador automático de fibras curtas aleatórias e longas para a análise de domínios elásticos tridimensionais; 
Os códigos computacionais foram desenvolvidos integralmente durante a pesquisa em linguagem de programação Fortran. Utilizou-se também, para a solução de sistemas lineares esparsos e simétricos, o código denominado de MA27 disponível em http://www.hsl.rl.ac.uk/ipopt. Os exemplos de sólidos bidimensionais desenvolvidos na etapa inicial tiveram suas malhas criadas empregando-se o pré-processador de acesso livre AcadMesh2D (PIEDADE NETO, D.; FAGÁ JÚNIOR, R.; PACCOLA, R. R, 2012) disponível em: http://www.set.eesc.usp.br/portal/pt/softwares, já para sólidos tridimensionais as malhas são criadas empregando-se o pré-processador do software comercial Ansys ${ }^{\circledR}$ e depois modificadas com a adição de nós a fim de se representar a aproximação de variáveis desejadas na simulação. Para visualizar os resultados obtidos, os códigos desenvolvidos foram acoplados a um programa de acesso livre para pós-processamento em elementos finitos $2 \mathrm{D}$ e 3D, denominado AcadView (PACCOLA, R. R.; CODA, H. B, 2005), que se encontra disponível em: http://www.set.eesc.usp.br/portal/pt/softwares.

\subsection{ORGANIZAÇÃO DA DISSERTAÇÃO}

Para apresentar a formulação desenvolvida e o resultado da pesquisa, este trabalho está organizado em cinco capítulos conforme descrito a seguir.

No Capítulo 1 apresenta-se uma introdução ao trabalho, descreve-se o que é o material compósito e suas classificações, apresenta-se o compósito com fibras e sua importância, bem como demais justificativas e objetivos desta pesquisa. Também se faz um breve comentário sobre a metodologia adotada para o desenvolvimento da formulação.

No Capítulo 2, apresenta-se uma breve revisão bibliográfica com os artigos mais importantes encontrado pelo autor. $\mathrm{Na}$ revisão se faz um breve relato sobre o desenvolvimento de estudos com fibras como reforço estrutural, apresenta-se alguns trabalhos de simulações numéricas que considerem matrizes reforçadas por fibras, e também não linearidade geométrica, por fim se faz um breve relato sobre o desenvolvimento do método dos elementos finitos posicional.

No Capítulo 3 descreve-se o problema de equilíbrio estático não linear geométrico, e apresentam-se algumas considerações para embasamento matemático do método adotado para análises numéricas neste trabalho. Também se descreve as formulações para os elementos de sólidos tetraédricos e de fibras. 
No Capítulo 4, são apresentados 5 exemplos para validar a formulação desenvolvida e implementada na presente pesquisa, além de mostrar o potencial de aplicação da mesma.

No Capítulo 5, tem-se as conclusões deste trabalho, considerações finais sobre a aplicabilidade da formulação e sugestões de pesquisas futuras.

Por fim, listam-se, em ordem alfabética, as referências bibliográficas consultadas para o desenvolvimento deste trabalho. 


\section{REVISÃO BIBLIOGRÁFICA}

Neste capítulo é apresentado um breve relato sobre a evolução dos estudos e aplicação dos materiais reforçados com fibras, além de alguns trabalhos desenvolvidos no que se refere às formulações computacionais para descrever o comportamento de sólidos, reforçados ou não com fibras, sujeitos às solicitações mecânicas.

\subsection{EVOLUÇÃO DOS ESTUDOS DE REFORÇOS COM FIBRAS}

Durante o século $\mathrm{XX}$, a investigação na área da ciência dos materiais proporcionou aos engenheiros explorarem uma nova gama de materiais que permitiriam a confecção de estruturas com propriedades mecânicas mais eficazes, leves, e por vezes mais baratas. A esta nova classe de materiais foi dado o nome de compósitos. Dentre os vários tipos de compósitos se destacam os materiais reforçados com fibras (BERNARDI, 2003).

O conceito de reforço com fibras nos materiais de construção não é algo novo. As fibras têm sido aplicadas em construções desde o início da história do homem; exemplos se referem a tijolos de adobe reforçados com fibras vegetais na Babilônia e Pérsia, pêlos de animais utilizados como reforço em argamassa de enchimento de paredes, tijolos de barro produzidos pelos egípcios com argila cozida e reforçados com palha. Entretanto, a adição de fibras para reforço do concreto é uma técnica de construção relativamente nova. O emprego de fibras descontínuas adicionadas ao concreto desenvolveu-se a partir de 1960 (LUBIN,1982), quando surgiram no mercado novos produtos tais como fibras metálicas, minerais e de vidro.

No Brasil, a utilização de fibras vegetais com a finalidade de reforço de matrizes começou na PUC-Rio em 1979 (BRESCANSIN, 2003), onde foram realizados estudos com fibras de coco reforçando argamassa de cimento. O interesse pelo uso das fibras naturais como reforço está vinculado ao seu baixo custo, disponibilidade e por questões ambientais e 
econômicas, já que os materiais tradicionais de construção apresentam um custo bastante elevado, explicado pelo alto consumo de energia na fabricação e também ao transporte. Este interesse se confirma ao se observar a evolução das publicações no que diz respeito ao estudo das fibras naturais na Figura 06. Os estudos relacionados às fibras naturais passaram a ser tão significativos que alguns autores adotaram o nome deste material como ECO - Compósito (MADGE, 1993). Hoje tanto fibras naturais quanto às sintéticas são largamente utilizadas.

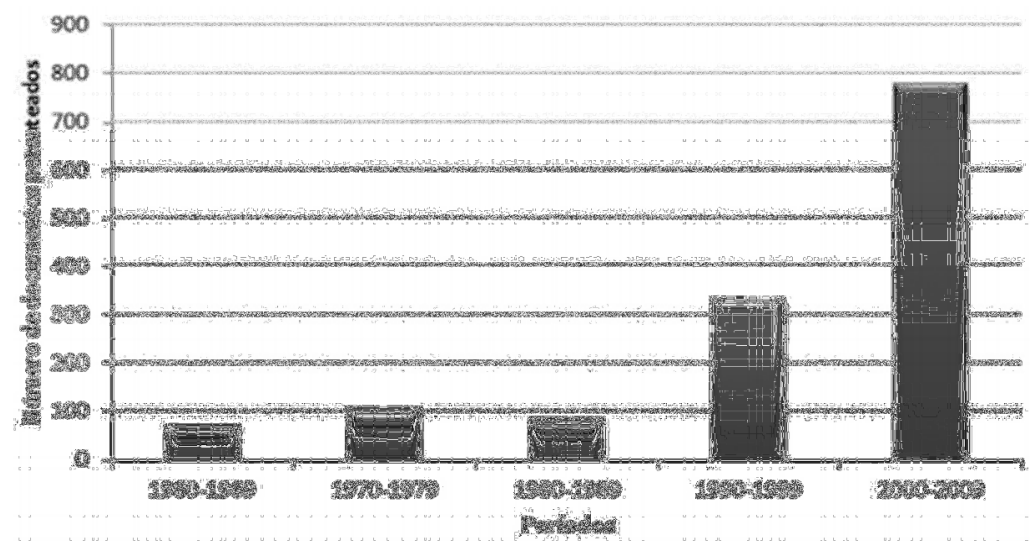

Figura 06 - Evolução do depósito de patentes internacionais relacionadas a fibras de sisal.

(Scopel, F.; Faria, L.I.L.; 2013)

Vários trabalhos relacionados à melhora de propriedades mecânicas alcançadas com a utilização de fibras em diferentes matrizes são encontrados na literatura especializada, sendo mais comum trabalhos com aplicação de matrizes de cimento (GUIMARÃES,1982; RYDER, 1970; BERNARDI, 2003). As fibras, em quantidades adequadas, modificam as características da matriz frágil e, de acordo com fatores como seu altíssimo módulo de elasticidade, elevada resistência à tração e pequeno coeficiente de Poisson, podem promover no compósito (GUIMARÃES,1982):

- Acréscimo na resistência à tração e flexão;

- Acréscimo na resistência ao impacto;

- Controle de fissuração e mudança de comportamento na ruptura, conferindo aumento na capacidade de carregamento após a fissuração da matriz. 
No entanto, essas melhorias podem ser, geralmente, acompanhadas por diminuição na resistência à compressão. Quando bem controlada, essa queda na resistência pode não comprometer o desempenho do compósito em serviço (GUIMARÃES,1982).

Com o desenvolvimento de formulações dos compósitos propriamente ditos, percebeu-se que os materiais reforçados com fibras poderiam ser aplicados em reparação de estruturas. Os primeiros registos comerciais utilizando compósitos em técnicas de reparação para estruturas tradicionais ocorreram no Japão na década de 80, e na Suíça em 1991 (MEIER, 2000).

Desde então, centenas de reparações com compósitos reforçados com fibras foram realizadas em estruturas por todo o mundo (MEIER, 2000), sendo alguns exemplos: pontes (RIZKALLA, 1999; HAYES, 2000), parques de estacionamento (RIZKALLA, 1999), estruturas de abóboda (BARBONI, 1997) e ferrovias em madeira (JACOB, 1997). Assim, verifica-se que estes materiais se aplicam de maneira muito eficaz na reparação, reforço e modernização de estruturas pré-existentes (KARBHARI, 1998).

Com o passar do tempo, os materiais compósitos reforçados com fibras passaram a ser importantes nas diversas indústrias de confecção, no entanto, o comportamento mecânico destes materiais é obtido principalmente com métodos empíricos o que leva em larga escala ao desperdício, e por vezes a um alto custo, como no caso da indústria aeronáutica, automobilística e biomecânica. Neste sentido, surgiu a necessidade de se desenvolver formulações numéricas mais realísticas para prever o comportamento desses materiais.

\subsection{SIMULAÇÃO NUMÉRICA DE COMPÓSITOS REFORÇADOS COM FIBRAS}

O estudo da condição de equilíbrio considerando os deslocamentos ocorridos durante o processo de mudança de configuração é conhecido como análise não-linear geométrica e seu principal objetivo é descrever a trajetória de equilíbrio de uma estrutura, ou seja, representar as configurações equilibradas correspondentes aos sucessivos níveis de força aplicada, identificar pontos críticos em que ocorre mudança da condição de equilíbrio de estável para instável e analisar a condição de estabilidade do equilíbrio associada a cada configuração (CRISFIELD, 1991). 
Para a consideração da não-linearidade geométrica na análise de estruturas através do Método dos Elementos Finitos, de maneira geral, duas formulações podem ser utilizadas: a Formulação Lagrangiana e a Formulação Euleriana (BATHE, 1982; CHAN, 1982).

Para a mecânica dos sólidos a formulação mais utilizada é a formulação Lagrangiana, pois no processo de solução, analisa-se com base na posição inicial, o comportamento de todas as partículas que constituem a estrutura, desde sua configuração inicial, $t=0$, até a configuração atualizada $t+\Delta t$, onde é possível estabelecer o equilíbrio. Logo na formulação Lagrangiana as variáveis são relacionadas a uma configuração conhecida (inicial). Outra formulação seria a formulação Euleriana, que é normalmente utilizada na Mecânica dos Fluidos. Simplificadamente pode-se dizer que na formulação Lagrangiana, as variáveis são sempre referenciadas à configuração inicial (formulação Lagrangiana Total), já na formulação Euleriana tais variáveis são sempre referenciadas à configuração final ou atual do corpo (CHAN, 1982).

Dentro das Formulações Lagrangianas, duas metodologias se destacam: a Formulação Lagrangiana Total (FLT) e a Formulação Lagrangiana Atualizada (FLA). Na FLT todas as variáveis estáticas e cinemáticas são referenciadas à configuração inicial, no tempo $\mathrm{t}=0$. Na FLA estas variáveis são referenciadas à última configuração equilibrada, tempo t, no qual, por exemplo, ocorre um incremento de carga.

A formulação Langrangiana, seja ela Total ou Atualizada é comum em trabalhos envolvendo comportamento mecânico de sólidos (MONDKAR e POWELL,1977; SURANA, 1983; LIAO e REDDY, 1990 ; GUMMADI e PALAZOTTO,1997; GRECO, 2004; CODA e GRECO, 2004; CODA e PACCOLA, 2007, 2008; PACCOLA et al. 2008; SAMPAIO, 2014; MOURA, 2015; NOGUEIRA, 2015).

Já a formulação Euleriana é mais comum em formulações envolvendo fluidos (NOLETO, 2010; DETTMER e PERIC, 2008; DONEA e HUERTA, 2003), porém pode ser encontrada em trabalhos relacionado ao comportamento de sólidos também (PAULA, 1997).

Descrever o equilíbrio considerando os deslocamentos inerentes do processo de deformação passa a ser significativo em estruturas esbeltas, em que pelo menos uma dimensão é bem superior às demais. Assim sendo, não é muito comum encontrar na literatura problemas de não-linearidade geométrica envolvendo sólidos tridimensionais na sua forma mais pura, ou seja, sem que haja nenhuma hipótese simplificadora para representar essas estruturas, como o caso de cascas, placas, ou mesmo pórticos tridimensionais, por exemplo. 
Isto devido ao alto custo computacional que elementos finitos tridimensionais geralmente impõem à solução (SAMPAIO, 2014).

Porém, com o aumento da capacidade de processamento dos computadores aliado à necessidade de se estudar corpos em que nenhuma das dimensões se destaca, trabalhos envolvendo este tipo de elemento passaram a ser desenvolvidos, dentre os quais podem ser citados:

Elwi e Hrudey (1989) apresentaram um modelo de acoplamento de sólidos 2D e 3D com elementos de barras de treliças. Tal modelo foi denominado pelos autores como incorporado, onde a geometria da fibra é consistente com a geometria da matriz, resultando em um único campo de deslocamentos no domínio do elemento, pois os segmentos das barras estão referenciados aos nós dos elementos da matriz implicando em uma aderência perfeita entre a matriz e a fibra. A mesma estratégia é encontrada em outros trabalhos (PRATES JR., 1992; CLAURE, 1994; MARTINELLI, 2003; VITORETTI, 2003; MEDEIROS, 2006). Uma estratégia semelhante pode ser encontrada nos trabalhos de Vanalli (2004), em Vanalli, Paccola e Coda (2008) e Sampaio (2014) os quais os autores utilizaram o método dos elementos finitos posicional com consideração de não linearidade física e (ou) geométrica para as modelagens.

Vanalli, Paccola e Coda (2008) e Sampaio (2014) observaram que uma ligação não conforme ocorre na interface fibra-matriz quando se acoplam elementos finitos de barra (fibra) e chapa (matriz) de graus diferentes de aproximação para as variáveis nodais. Neste sentido, para uma conformidade entre os diferentes domínios, faz-se necessária a utilização de aproximações para os graus de liberdade das fibras no mínimo iguais às utilizadas para a matriz.

Mesehke e Helnwein (1994) apresentaram uma formulação numérica de um elemento finito hexaédrico de 20 nós enrijecido com elementos de barras em algumas direções para análise de materiais hiperelásticos sofrendo grandes deformações. Tal formulação foi confrontada com modelos constitutivos neo-Hookeanos e de Saint Venant-Kirchhoff previamente estabelecidos, obtendo-se resultados satisfatórios.

Duarte et al. (2000) desenvolveram uma formulação linear geométrica para elementos finitos tetraédricos generalizados, comparando os resultados da formulação com a teoria clássica de elementos finitos, mostrando que, como era esperado, para os elementos finitos generalizados foram necessários menos elementos para se alcançar os resultados esperados. 
Yang et al. (2000) discutiram os elementos finitos tridimensionais como uma proposta geral para problemas arbitrários da mecânica dos sólidos, destacando vantagens destes tipos de elementos, como formulação numérica simples, pois a utilização de elementos sólidos tridimensionais evita a necessidade de introdução de rotações finitas como variáveis no problema, necessárias em algumas formulações para a análise de cascas finas. Esses elementos permitem a aplicação direta de equações constitutivas tridimensionais, além de não apresentarem travamento em análises de elementos muito finos, o que possibilita análises de estruturas de placas e cascas através do uso de elementos de sólidos. A desvantagem neste caso fica por conta do custo computacional.

Medeiros (2006) desenvolveu em linguagem Fortran 90 elementos finitos tridimensionais hexaédricos de primeira e segunda ordem, com elementos finitos de barra de treliça acoplados a matriz para representar a armadura. Tal formulação foi aplicada em análises não-lineares de estruturas de fundações e interação solo-estrutura. Embora a formulação apresentada seja simples, o autor relata problemas com a velocidade de processamento em computadores com arquitetura de memória em 32 bits.

Hron e Mádilk (2006) desenvolveram uma formulação acoplando fluido-estrutura aplicada a problemas de biomecânica, utilizando elementos finitos sólidos tetraédricos de 10 nós.

Maciel (2008) apresentou uma formulação não-linear geométrica de elementos finitos de sólidos $2 \mathrm{D}$ e 3D de primeira e segunda ordem com elementos triangulares, quadrilaterais, tetraédricos, hexaédricos e prismáticos, validando a formulação obtida com soluções analíticas encontradas na literatura.

Manzoli et al. (2008) descreveram uma metodologia para modelar elementos estruturais de concreto armado tridimensionais (tetraédricos), com descontinuidade incorporada no contexto da aproximação contínua de descontinuidades fortes, para simular a propagação de fissuras no meio continuo. Já Shinya et al. (2009) estudou em termos de elementos finitos tridimensionais a eficiência dos reforços com fibras em próteses de partes fixas. O autor concluiu que para cargas aplicadas lateralmente a eficiência é baixa, porém em cargas axiais o reforço com fibra se mostrou bastante eficaz. 


\subsection{ELEMENTOS FINITOS POSICIONAL APLICADOS EM COMPÓSITOS REFORÇADOS COM FIBRAS}

O método dos elementos finitos posicional, como o próprio nome sugere, apresenta como principal característica o emprego de graus de liberdade em posições, ao invés dos tradicionais deslocamentos. Os primeiro trabalhos relacionados ao MEFP são os de Bonet et al (2000) e Coda (2003)

Aplicações e desenvolvimentos deste método são encontrados na resolução de diversos problemas não lineares, tais como: análises não-lineares geométricas de pórticos $2 \mathrm{D}$ e 3D, placas e cascas (CODA; PACCOLA, 2007; CODA, 2009; CODA; PACCOLA; SAMPAIO, 2013); análises não-lineares físicas e geométrica de sólidos tridimensionais com consideração de leis constitutivas hiperelásticas (PASCON, 2012; PASCON; CODA, 2013); análises não-lineares físicas de chapas, placas e cascas, homogêneas e laminadas (PACCOLA, 2004; VANALLI, 2004); problemas de contato em elementos finitos de barra geral e chapa (GRECO, 2004; CARRAZEDO; CODA, 2006); interação solo-estrutura (SILVA, 2014) e fluido-estrutura (SANCHES, 2011; SANCHES; CODA, 2014; NOGUEIRA, 2015); análises dinâmicas em elementos finitos de sólidos tridimensionais e barra geral tridimensional (MACIEL; CODA, 2010; CODA; PACCOLA, 2011); análises de materiais compósitos reforçados com fibras e laminados (SAMPAIO, 2014; SAMPAIO; PACCOLA; CODA, 2015) e análise de compósitos particulados (MOURA, 2015). Estes trabalhos exemplificam a grande capacidade da formulação posicional de resolver os mais diversos tipos de problemas e foram desenvolvidos no âmbito do Grupo de Mecânica Computacional - GMEC/SET/EESC/USP, grupo de pesquisa no qual se insere o presente trabalho. 


\section{ELEMENTO FINITO DE SÓLIDO TRIDIMENSIONAL REFORÇADO POR FIBRAS}

Neste capítulo são apresentados os conceitos necessários para o desenvolvimento da formulação numérica implementada na presente pesquisa.

\subsection{PROBLEMAS ELÁSTICOS TRIDIMENSIONAIS}

O problema central da elasticidade não-linear tridimensional consiste em encontrar a posição de equilíbrio de um corpo elástico, que após ser submetido a um conjunto de forças aplicadas passa de uma configuração de referência $\Omega^{0}$ a uma configuração deformada $\Omega$, caracterizada por um mapeamento $\varphi$ chamado de função mudança de configuração (CIARLET, 1988).

Desta forma, seja $\Omega^{0}$ a configuração inicial de referência indeformada de um corpo, $\Omega$ a configuração atual e deformada após sofrer qualquer tipo de solicitação mecânica (Figura 07).

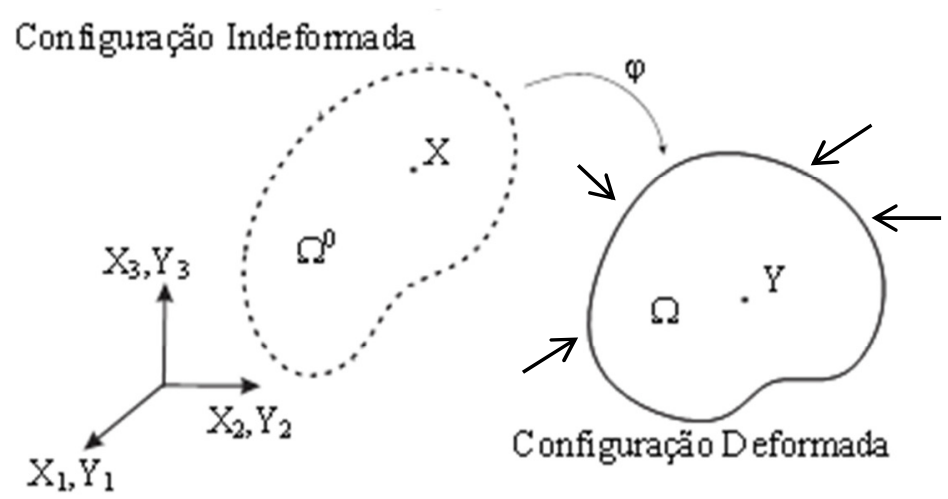

Figura 07 - Referencial Lagrangiano para a mudança de configuração - adaptado de Sampaio (2014) 
Na Figura 07, se observa que o espaço vetorial de referência é considerado fixo. A este modelo se da o nome de Lagrangiano Total.

Sob a ação das forças externas, o corpo se deforma e se desloca e os pontos pertencentes à configuração inicial $\Omega^{0}$ passam a ser representados por pontos pertencentes à configuração final $\Omega$ caracterizando a mudança de configuração do corpo. Para o desenvolvimento da formulação parte-se do princípio que existe uma função $\varphi$ que, embora desconhecida, seja capaz de descrever esta mudança de posição e forma que o corpo apresenta após sofrer as solicitações.

O processo de mudança de configuração é governado pela primeira lei da termodinâmica (TAUCHERT, 1974), o sistema é adiabático, portanto conservativo. A expressão do potencial total de energia do sistema é dada por:

$\Pi=U+T$

Sendo П o potencial total de energia do sistema, U a energia de deformação do corpo, que será descrita posteriormente neste trabalho, e $\mathrm{T}$ a energia potencial das forças externas, que é dada por:

$T=-F_{i} Y_{i}$

sendo $F_{i}$ as forças externas aplicadas e $Y_{i}$ as coordenadas que determinam a posição de aplicação das referidas forças.

Entre o instante em que as cargas são aplicadas até o corpo encontrar a posição de equilíbrio, ocorre uma variação do tempo. Logo, o corpo desenvolve também uma parcela de energia cinética. Neste trabalho, tanto a variação do tempo quanto a parcela de energia cinética contida no processo são desprezadas, portanto, o processo é estático. Em Maciel (2008) é encontrada a formulação dinâmica, via Método dos elementos finitos posicional, para sólidos tridimensionais.

Segundo Tauchert (1974), para a posição de equilíbrio a energia potencial total passa por um valor estacionário, se este valor for um ponto de mínimo o equilíbrio é dito estável, tal princípio é conhecido como Princípio da Estacionariedade. 
Com isso para a posição de cada nó referenciado em cada direção no equilíbrio se tem:

$$
G_{i}=\frac{\partial \Pi}{\partial Y_{i}}=\frac{\partial U}{\partial Y_{i}}-F_{i}=F_{i}^{I N T}-F_{i}=0
$$

Na Equação (3.3), $F_{i}^{I N T}$ representa o vetor de forças internas do problema, uma vez que ao se derivar a energia de deformação em relação às direções se encontram forças, e $Y_{i}$ são as posições dos nós incógnitas do problema.

Em qualquer situação para a posição atual $Y_{i}$ que não a de equilíbrio, o vetor $\vec{G}$ passa a não ser nulo, se tornando um vetor de desbalanceamento. O sistema de equações para encontrar as posições de equilíbrio para o corpo é não-linear, aplicando-se para tanto o método de Newton-Raphson para resolução do sistema. Neste método a resolução acontece a partir de uma posição atual conhecida $Y_{i}^{0}$. Expandindo-se o vetor de desbalanceamento $\vec{G}$ em série de Taylor e truncando no primeiro termo se obtém:

$G_{j}\left(Y_{i}\right)=G_{j}\left(Y_{i}^{0}\right)+\left.\frac{\partial G_{j}}{\partial Y_{k}}\right|_{Y_{i}^{0}} \Delta Y_{k}=0$

Pode-se isolar o incremento de posição $\Delta Y_{k}$ :

$$
\Delta Y_{k}=-\left(\left.\frac{\partial G_{j}}{\partial Y_{k}}\right|_{Y_{i}^{0}}\right)^{-1} \cdot G_{j}\left(Y_{i}^{0}\right)
$$

O termo $\left.\frac{\partial G_{j}}{\partial Y_{k}}\right|_{Y_{i}^{0}}$ é a matriz Hessiana do problema, também denominada matriz de rigidez, melhor ilustrada na Equação (3.6).

$$
\left.\frac{\partial G_{j}}{\partial Y_{k}}\right|_{Y_{i}^{0}}=\left.\frac{\partial^{2} U}{\partial Y_{k} \partial Y_{i}}\right|_{Y_{i}^{0}}
$$


Após se definir a correção da posição $\Delta Y_{k}$, se corrige a posição tentativa conforme a Equação (3.7) e se reinicia o processo.

$Y_{i}=Y_{i}^{0}+\Delta Y_{k}$

A cada vez que a posição tentativa é corrigida, o módulo do vetor de correção $\overrightarrow{\Delta Y}$ diminui, e o critério de parada para a atualização da posição é baseado neste valor, comparando-se a uma tolerância pré-estabelecida, ou seja:

$$
\frac{\left|\overrightarrow{\Delta Y_{k}}\right|}{|\vec{X}|}<\text { tolerância } \rightarrow \text { Equilíbrio }
$$

\subsection{CINEMÁTICA PARA O MEIO CONTÍNUO}

A cinemática descrita neste item, embora resolva qualquer sólido contínuo foi particularizada para o elemento finito tetraédrico, o qual foi utilizado neste trabalho. Aspectos teóricos relativos à cinemática, no âmbito da Mecânica Não Linear do Contínuo, podem ser encontrados, por exemplo, em Coimbra (1981), Ogden (1984), Ciarlet (1988), Khan e Huang (1995), Belytschko, et al. (2000), Crisfield (1991), Holzapfel (2000), Pascon (2008; 2012).

Segundo Holzapfel (2000), a grandeza função mudança de configuração é uma função em um campo vetorial que associa os infinitos pontos materiais do sólido às suas respectivas posições no espaço. Tal associação deve ser feita em relação a um referencial, que é um conjunto de eixos cartesianos com origem fixa. As posições iniciais e atuais são representadas, respectivamente, pelos campos vetoriais X e Y. Além disso, a descrição adotada aqui é a Lagrangiana, isto é, a posição de referência é sempre a inicial (X) indeslocada e indeformada.

Para mapear as configurações inicial e final do elemento finito tetraédrico, é empregado o mapeamento posicional duplo, usado em Coda e Paccola (2007) e Pascon 
(2008). Assim sendo, as configurações inicial e final são parametrizadas por meio dos valores nodais de um espaço auxiliar adimensional, representado por $\xi$.

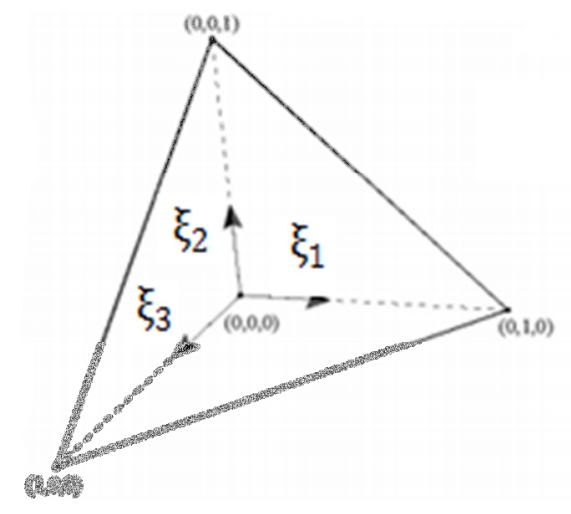

Figura 08 - Espaço adimensional ( $\xi$ ) do tetraedro - adaptado de Pascon (2012)

As posições $\left(\mathrm{x}_{1}, \mathrm{x}_{2}, x_{3}\right)$ de um ponto qualquer na configuração inicial $\Omega^{0}$ são relacionadas às coordenadas adimensionais $\left(\xi_{1}, \xi_{2}, \xi_{3}\right)$ do ponto através das funções de forma $\emptyset\left(\xi_{1}, \xi_{2}, \xi_{3}\right)$ e dos valores das posições $\left(\mathrm{X}_{1}, \mathrm{X}_{2}, \mathrm{X}_{3}\right)$ dos $l$ nós pertencentes ao elemento finito onde o ponto se encontra, como apresentado na Equação (3.9).

$x_{i}=\emptyset_{l}\left(\xi_{1}, \xi_{2}, \xi_{3}\right) X_{l}^{i}$

Um raciocínio análogo é utilizado para mapear as posições do ponto da configuração atual $\Omega$, como:

$y_{i}=\emptyset_{l}\left(\xi_{1}, \xi_{2}, \xi_{3}\right) Y_{l}^{i}$

As funções de forma de ordem qualquer assumem valor unitário para o nó onde foram definidas e zero nos demais nós do elemento e podem ser determinadas para qualquer grau de aproximação adotado para as variáveis nodais seguindo ideia apresentada no trabalho de Pascon (2012).

A função mudança de configuração $\varphi$ que mapeia os pontos com coordenadas $X_{l}^{i}$ da configuração inicial $\Omega^{0}$ e os pontos com coordenadas $Y_{l}^{i}$ da configuração atual $\Omega$, é desconhecida. Tal função pode ser escrita como uma composição dos mapeamentos $\varphi^{0}$, da 
configuração auxiliar $\Omega^{1}$ na configuração inicial $\Omega^{0}$,e $\varphi^{1}$, da configuração auxiliar $\Omega^{1}$ na configuração atual $\Omega$, pela expressão (3.11), e exemplificado na Figura 09, que, embora represente um sólido bidimensional, possui um raciocínio análogo para o caso tridimensional.

$\varphi=\varphi^{1}\left(\varphi^{0}\right)^{-1}$

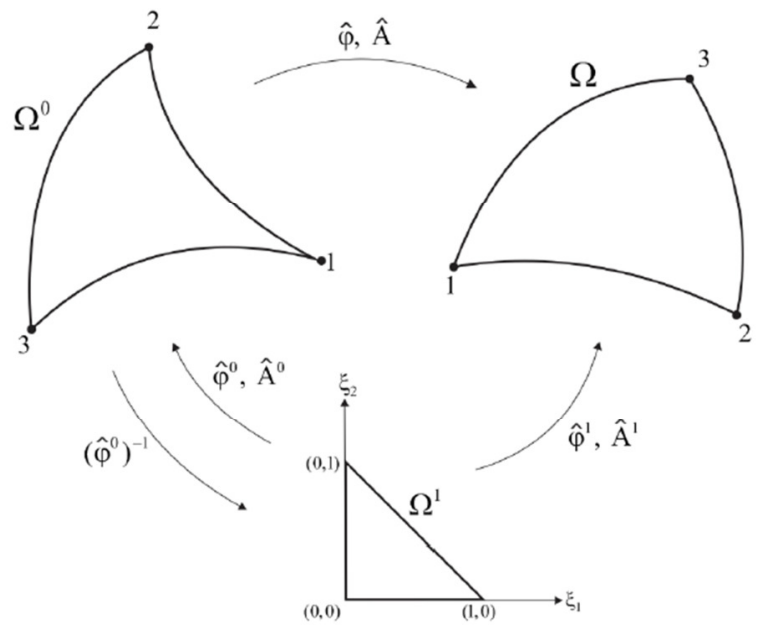

Figura 09 - Mapeamento no espaço adimensional ( $\xi$ ). (SAMPAIO, 2014)

Para analisar a mudança de forma de um corpo emprega-se o tensor gradiente da função mudança de configuração, também chamado simplesmente de gradiente (PASCON, 2008). Na Figura 09 se assume que $\varphi(X)$ é uma função matemática, portanto é possível conhecer pontos a vizinhança de um ponto inicial conhecido $\varphi\left(\mathrm{X}_{0}\right)$.

$\varphi(\mathrm{X} 1, \mathrm{X} 2, \mathrm{X} 3)=\varphi\left(\mathrm{X} 1_{0}, \mathrm{X} 2_{0}, \mathrm{X} 3_{0}\right)+\left.\frac{\partial \varphi}{\partial X 1}\right|_{X_{0}} \Delta X 1+\left.\frac{\partial \varphi}{\partial X 2}\right|_{X_{0}} \Delta X 2+\left.\frac{\partial \varphi}{\partial X 3}\right|_{X_{0}} \Delta X 3$

Como é uma relação diferencial, $\Delta X \rightarrow 0$, portanto a relação pode ser escrita:

$\mathrm{dY}=\left.\boldsymbol{\operatorname { G r a d }} \varphi\right|_{X_{0}} d x$

Os gradientes dos mapeamentos $\varphi^{0} \mathrm{e} \varphi^{1}$ são designados, respectivamente, como $A^{0} \mathrm{e}$ $A^{1}$, e compõem o gradiente $A$ da função mudança de configuração $\varphi$, sendo: 
$A_{i j}^{0}=\frac{\partial \varphi_{k}^{0}}{\partial \xi_{j}} X_{i}^{k}, A_{i j}^{1}=\frac{\partial \varphi_{k}^{0}}{\partial \xi_{j}} Y_{i}^{k}$

O gradiente da função mudança de configuração pode ser escrito como:

$A_{i j}=A_{i k}^{1}\left(A^{0}\right)^{-1}{ }_{k j}$

Partindo da expressão (3.13) pode-se deduzir que:

$\mathrm{dY}=\mathrm{AdX} \rightarrow \mathrm{dY} \mathrm{Y}^{t}=d X^{t} A^{t} \rightarrow d Y^{2}=A^{t} A d X^{2}$

Segundo Coimbra (1981), a mudança de configuração é de corpo rígido quando o produto $A^{t} A$ resulta na matriz identidade $I$. Ao produto $A^{t} A$ se da o nome de $C$, tensor de alongamento à direita de Cauchy-Green. O tensor $C$ é sempre positivo e simétrico, em outras palavras o material jamais sofre aniquilamento. Conforme afirmado em Coimbra (1981), esse tensor é uma medida de desvio entre uma determinada mudança de forma e um movimento de corpo rígido.

Por definição a medida de deformação da lei constitutiva de Saint-Venant-Kirchhoff é expressa por:

$\mathrm{E}=\frac{1}{2}(C-I)$

A esse tensor (E) se dá o nome de tensor de deformações de Green-Lagrange. 


\subsubsection{ENERGIA DE DEFORMAÇÃO}

A energia especifica de deformação na lei elástico linear de Saint-Venant-Kirchhoff é calculada de maneira análoga à da lei de Hooke:

$u=\frac{1}{2}(E: K: E)$

Onde $K$ é um tensor de quarta ordem que representa as constantes elásticas da lei constitutiva de Saint-Venant-Kirchhoff. A energia de deformação $U$ é obtida ao se integrar a energia específica de deformação no volume do corpo.

$U=\int_{d V_{0}} u d V_{0}$

A energia específica de deformação é obtida tendo como referencia o volume inicial do corpo $V_{0}$, formulação Lagrangiana Total. Pode-se utilizar o espaço adimensional como mapeamento da configuração inicial assim sendo:

$U=\iiint u\left(\xi_{1}, \xi_{2}, \xi_{3}\right) . J\left(\xi_{1}, \xi_{2}, \xi_{3}\right) d \xi_{1} d \xi_{2} d \xi_{3}$

O escalar $J$ é o jacobiano presente na mudança de variáveis ocorrida quando se mapeia da configuração inicial para o espaço adimensional:

$J=\left\|A^{0}\right\|$

Obtém-se o resultado da expressão (3.20) através de uma estratégia de integração numérica (Quadratura Gaussiana), onde a energia de deformação de um único elemento tetraédrico é expressa por: 
$U=\sum_{n=1}^{N . P . \text { de Gauss }} u\left(\xi_{1}, \xi_{2}, \xi_{3}\right)_{n} \cdot J\left(\xi_{1}, \xi_{2}, \xi_{3}\right)_{n} \cdot P_{n}$

A integral é substituída por um somatório dos valores de $u$ calculados em pontos pré determinados chamados de pontos de Gauss, e multiplicados pelos respectivos pesos de integração $P_{n}$. A energia de deformação total do meio contínuo pode ser obtida somando as parcelas de todos os elementos finitos que compõem o modelo em análise.

\subsubsection{CONSIDERAÇÕES PARA O SÓLIDO}

As forças internas nodais do sólido são obtidas a partir da primeira derivada da energia de deformação, dadas por:

Fint $_{J}^{I}=\iiint \frac{\partial u}{\partial Y_{J}^{I}} J\left(\xi_{1}, \xi_{2}, \xi_{3}\right) d \xi_{1} d \xi_{2} d \xi_{3}$

Nota-se nas equações (3.17) e (3.18) que para se derivar a energia de deformação em termos das posições nodais se faz necessário o uso da regra da cadeia, logo a Equação (3.23) também pode ser expressa por:

Fint $_{J}^{I}=\iiint \frac{\partial u}{\partial E}: \frac{\partial E}{\partial C}: \frac{\partial C}{\partial Y_{J}^{I}} J\left(\xi_{1}, \xi_{2}, \xi_{3}\right) d \xi_{1} d \xi_{2} d \xi_{3}$

Ao se desenvolver os termos contidos na integral, se pode escrever o termo diferencial da Equação (3.23) como:

$\frac{\partial u}{\partial Y_{J}^{I}}=\frac{1}{2} S: \frac{\partial C}{\partial Y_{J}^{I}}$ 
Sendo S é o tensor de tensões de Piola-Kirchhoff de segunda espécie. Pode-se ainda desenvolver o termo $\frac{\partial \mathrm{C}}{\partial \mathrm{Y}_{\mathrm{J}}^{\mathrm{I}}}$ como:

$$
\frac{\partial C}{\partial Y_{J}^{I}}=\left(A^{0}\right)^{-T} \cdot \frac{\partial\left(A^{1}\right)^{T}}{\partial Y_{J}^{I}} \cdot A^{1} \cdot\left(A^{0}\right)^{-1}+\left(A^{0}\right)^{-T} \cdot\left(A^{1}\right)^{T} \cdot \frac{\partial\left(A^{1}\right)}{\partial Y_{J}^{I}} \cdot\left(A^{0}\right)^{-1}
$$

Para resolver o sistema resultante é necessário calcular a segunda derivada em termos das posições nodais, obtendo-se a matriz Hessiana, ou matriz de rigidez tangente, completando assim todas as variáveis do processo.

$$
H_{E S S_{I J K L}}=\frac{\partial^{2} U}{\partial Y_{J}^{I} \partial Y_{L}^{K}}=\frac{1}{4} \frac{\partial^{2} U}{\partial E \partial E}: \frac{\partial C}{\partial Y_{L}^{K}}: \frac{\partial C}{\partial Y_{J}^{I}}+\frac{1}{2} \frac{\partial u}{\partial E}: \frac{\partial^{2} C}{\partial Y_{L}^{K} \partial Y_{J}^{I}}
$$

A Equação (3.27) é obtida a partir da derivada da Equação (3.23), onde $\frac{\partial^{2} \mathrm{U}}{\partial \mathrm{E} \partial \mathrm{E}}$ é o tensor constitutivo do problema. Desenvolvendo-se o termo $\frac{\partial^{2} \mathrm{C}}{\partial \mathrm{Y}_{\mathrm{L}}^{\mathrm{K}} \partial \mathrm{Y}_{\mathrm{J}}^{1}}$ obtém-se:

$\frac{\partial^{2} C}{\partial Y_{L}^{K} \partial Y_{J}^{I}}=\left(A^{0}\right)^{-T} \cdot \frac{\partial\left(A^{1}\right)^{T}}{\partial Y_{J}^{I}} \cdot \frac{\partial\left(A^{1}\right)}{\partial Y_{L}^{K}} \cdot\left(A^{0}\right)^{-1}+\left(A^{0}\right)^{-T} \cdot \frac{\partial\left(A^{1}\right)^{T}}{\partial Y_{L}^{K}} \cdot \frac{\partial\left(A^{1}\right)}{\partial Y_{J}^{I}} \cdot\left(A^{0}\right)^{-1}$

\subsubsection{CONSIDERAÇÕES PARA AS FIBRAS}

Ao se simular elementos de sólidos de alta ordem com fibras de baixa ordem gera-se um modelo não conforme, ou seja, não se garante a total conformidade entre as os elementos de fibra e sólido (SAMPAIO, 2014). Portanto neste trabalho foi deduzida uma formulação para fibras de ordem qualquer. 


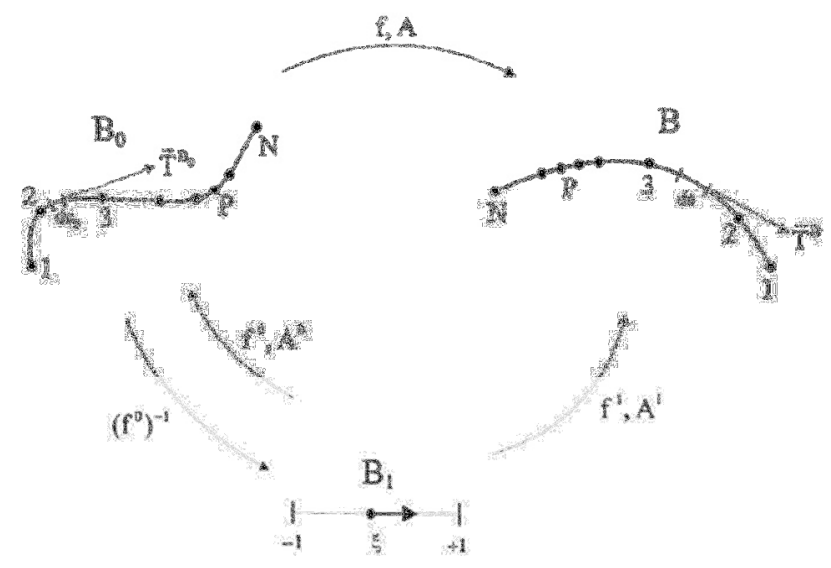

Figura 10 - Mapeamento das fibras no espaço adimensional ( $\xi)$. (SAMPAIO, 2013)

Assim como apresentado para o elemento tetraédrico, emprega-se o mapeamento posicional duplo para mapear as configurações inicial e final da fibras, Figura 10.

$x_{i}=\Phi_{l}(\xi) X_{l}^{i}$

$y_{i}=\Phi_{l}(\xi) Y_{l}^{i}$

O vetor tangente, e respectivo módulo, a um determinado ponto do elemento de fibra é dado por:

$$
\begin{aligned}
T_{i}^{B 0} & =\frac{\partial \Phi_{l}(\xi)}{\partial \xi} X_{l}^{i} \\
\left|T^{B 0}\right| & =\sqrt{\left(\frac{\partial \Phi_{l}(\xi)}{\partial \xi} X_{l}^{1}\right)^{2}+\left(\frac{\partial \Phi_{l}(\xi)}{\partial \xi} X_{l}^{2}\right)^{2}+\left(\frac{\partial \Phi_{l}(\xi)}{\partial \xi} X_{l}^{3}\right)^{2}}
\end{aligned}
$$


Em termos das posições atuais:

$T_{i}^{B}=\frac{\partial \Phi_{l}(\xi)}{\partial \xi} Y_{l}^{i},\left|T^{B}\right|=\sqrt{\left(\frac{\partial \Phi_{l}(\xi)}{\partial \xi} Y_{l}^{1}\right)^{2}+\left(\frac{\partial \Phi_{l}(\xi)}{\partial \xi} Y_{l}^{2}\right)^{2}+\left(\frac{\partial \Phi_{l}(\xi)}{\partial \xi} Y_{l}^{3}\right)^{2}}$

De maneira similar a Equação (3.21), para o caso das fibras o jacobiano pode ser expresso por:

$J=\left|T^{B 0}\right|$

A partir dos módulos dos vetores tangentes nas configurações inicial e atual dados nas Equações (3.31) e (3.32), define-se a medida de deformação de Green E em função das posições nodais do elemento finito de fibra curvo:

$E=\frac{1}{2}\left(\frac{\left|T^{B}\right|^{2}}{\left|T^{B 0}\right|^{2}}-1\right)$

ou em sua forma expandida:

$E=\frac{1}{2}\left\{\frac{\left[\left(\frac{\partial \Phi_{l}(\xi)}{\partial \xi} Y_{l}^{1}\right)^{2}+\left(\frac{\partial \Phi_{l}(\xi)}{\partial \xi} Y_{l}^{2}\right)^{2}+\left(\frac{\partial \Phi_{l}(\xi)}{\partial \xi} Y_{l}^{3}\right)^{2}\right]}{\left[\left(\frac{\partial \Phi_{l}(\xi)}{\partial \xi} X_{l}^{1}\right)^{2}+\left(\frac{\partial \Phi_{l}(\xi)}{\partial \xi} X_{l}^{2}\right)^{2}+\left(\frac{\partial \Phi_{l}(\xi)}{\partial \xi} X_{l}^{3}\right)^{2}\right]}-1\right\}$

Ainda para a fibra, utiliza-se lei constitutiva de Saint-Venant-Kirchhoff, logo a energia especifica de deformação é a mesma definida na Equação (3.18). A energia de deformação total do elemento finito de fibra também é obtida integrando-se a energia específica no volume da fibra. Segundo Hyer e White (1998) uma fibra deve possuir uma dimensão que se destaca sobre as outras duas. Logo é concebível afirmar que as áreas da seção transversal da 
mesma são suficientemente pequenas e constantes, assim a energia de deformação é expressa por:

$U=\int_{0}^{l} u \cdot A \cdot d l$

onde A é a área da seção transversal da fibra no seu volume inicial e l seu comprimento inicial. Pode-se descrever a Equação (3.36) em termos do espaço adimensional por:

$U=\int_{-1}^{1} u \cdot A \cdot\left|T^{B 0}\right| \cdot d \xi$

Já as componentes do vetor de forças internas nodais são definidas como:

$$
\begin{aligned}
\text { Fint }_{J}^{I}= & \frac{\partial U}{\partial Y_{J}^{I}}=\int_{-1}^{1} K \cdot E \cdot \frac{\partial E}{\partial Y_{J}^{I}} A \cdot\left|T^{B 0}\right| \cdot d \xi \\
& \text { O termo } \frac{\partial \mathrm{E}}{\partial \mathrm{Y}_{\mathrm{J}}^{I}} \text { pode ser expandido da seguinte forma: }
\end{aligned}
$$

$$
\frac{\partial E}{\partial Y_{J}^{i}}=\frac{\left(\frac{\partial \Phi_{l}(\xi)}{\partial \xi} Y_{l}^{i}\right) \frac{\partial \Phi_{j}(\xi)}{\partial \xi}}{\left|T^{B 0}\right|^{2}}
$$

De maneira análoga ao sólido a matriz de rigidez tangente da fibra é expressa como a segunda derivada da energia de deformação, ou seja:

$$
H E S S_{I J K L}=\frac{F(I N T)_{J}^{I}}{\partial Y_{L}^{k}}=\frac{\partial^{2} U}{\partial Y_{J}^{I} \partial Y_{L}^{K}}
$$


Desenvolvendo-se a derivada a partir da Equação (3.38) obtém-se:

$H E S S_{I J K L}=\left(\int_{-1}^{1} \frac{K}{\left|T^{B 0}\right|^{2}} \frac{\partial \Phi_{P}(\xi)}{\partial \xi} Y_{P}^{K} \frac{\partial \Phi_{L}(\xi)}{\partial \xi} \frac{\partial \Phi_{P}(\xi)}{\partial \xi} Y_{P}^{I} \frac{\partial \Phi_{j}(\xi)}{\partial \xi}+K \cdot E \cdot \frac{\partial \Phi_{L}(\xi)}{\partial \xi} \frac{\partial \Phi_{j}(\xi)}{\partial \xi} \delta_{I K}\right) A \cdot\left|T^{B 0}\right| \cdot d \xi$

\subsubsection{ACOPLAMENTO FIBRA - SÓLIDO}

Vanalli (2004) apresentou um procedimento para inserir fibras em qualquer domínio sem aumentar a ordem do sistema de equações resultante, ao mesmo tempo em que os nós das fibras não necessitam coincidir com os nós dos elementos da matriz. A mesma estratégia foi adotada neste trabalho e consiste em descrever as posições dos nós dos elementos de fibras em função das posições dos nós dos elementos de sólidos onde elas estão imersas, como mostra a Equação (3.42).

$X_{\text {fibra }}^{i}=\varphi_{l}\left(\xi_{1}^{f}, \xi_{2}^{f}, \xi_{3}^{f}\right) X_{l}^{i}$

Sendo $\xi_{\mathrm{i}}^{\mathrm{f}}$ são as coordenadas adimensionais do nó da fibra, $\varphi_{1}$, as funções de forma do elemento tetraédrico e $X_{l}^{i}$ as posições dos nós do elemento tetraédrico. Em termos de posições atuais:

$Y_{\text {fibra }}^{i}=\varphi_{l}\left(\xi_{1}^{f}, \xi_{2}^{f}, \xi_{3}^{f}\right) Y_{l}^{i}$

A energia específica de deformação do material reforçado por fibras, passa a ser a soma das energias específicas de deformação da matriz e da fibra.

$U_{T}=U_{M}+U_{F}$ 
Portanto, o vetor de forças internas do material reforçado, pode ser explicitado pela Equação (3.45).

$$
\frac{\partial\left(U_{M}+U_{F}\right)}{\partial Y_{J}^{I}}=\text { Fint }_{J}^{I}
$$

Pode-se escrever a Equação (3.45) em função das posições nodais, onde observa-se que a energia de deformação das fibras é escrita em função das coordenadas nodais da matriz.

$$
F_{i n t}^{I}=\frac{\partial\left(U_{M}+U_{F}\right)}{\partial Y_{J}^{I}}=\int_{V 0} \frac{\partial U_{M}(Y M)}{\partial Y_{J}^{I}} d V 0+\int_{V 0} \frac{\partial U_{F}(Y F(Y M))}{\partial Y_{J}^{I}}
$$

O primeiro termo da Equação (3.46) pode ser expandido.

$$
\frac{\partial U_{M}(Y M)}{\partial Y_{J}^{I}}=\frac{1}{2} S:\left(\left(A^{0}\right)^{-T} \cdot \frac{\partial\left(A^{1}\right)^{T}}{\partial Y_{J}^{I}} \cdot A^{1} \cdot\left(A^{0}\right)^{-1}\left(A^{0}\right)^{-T} \cdot\left(A^{1}\right)^{T} \cdot \frac{\partial\left(A^{1}\right)}{\partial Y_{J}^{I}} \cdot\left(A^{0}\right)^{-1}\right)
$$

Já o segundo termo, é obtido a partir da regra da cadeia, e pode ser expandido da seguinte forma:

$$
\frac{\partial U_{F}(Y F(Y M))}{\partial Y_{J}^{I}}=\frac{\partial U_{F}(Y F(Y M))}{\partial Y F_{a}^{b}} \frac{\partial Y F_{a}^{b}}{\partial Y_{J}^{I}}=K . E . \frac{\left(\frac{\partial \Phi_{l}(\xi)}{\partial \xi} Y_{l}^{b}\right) \frac{\partial \Phi_{i}(\xi)}{\partial \xi}}{\left|T^{B 0}\right|^{2}} . \Phi_{j}\left(\xi_{a}^{1}, \xi_{a}^{2}, \xi_{a}^{3}\right) \delta a j
$$

De maneira análoga se obtém a segunda derivada da energia de deformação, como a somatória das segundas derivadas das parcelas da matriz e do reforço:

$$
H_{E S S_{I J K L}}=\int_{V 0} \frac{\partial^{2} U_{M}(Y M)}{\partial Y_{J}^{I} \partial Y_{L}^{K}}+\frac{\partial^{2} U_{F}(Y F(Y M))}{\partial Y_{J}^{I} \partial Y_{L}^{K}} d V 0
$$


O primeiro termo da Equação (3.49), está expandido na Equação (3.27), já o segundo termo é expandido da seguinte forma:

$\frac{\partial^{2} U_{F}(Y F(Y M))}{\partial Y_{J}^{I} \partial Y_{L}^{K}}=\frac{\partial^{2} U_{F}}{\partial Y_{b}^{a} \partial Y_{b}^{a}} \frac{\partial Y_{b}^{a} \partial Y_{b}^{a}}{\partial Y_{J}^{I} \partial Y_{L}^{K}}+\frac{\partial^{2} U_{F}}{\partial Y_{b}^{a} \partial Y_{d}^{c}} \frac{\partial Y_{b}^{a} \partial Y_{d}^{c}}{\partial Y_{J}^{I} \partial Y_{L}^{K}}+\frac{\partial^{2} U_{F}}{\partial Y_{d}^{c} \partial Y_{b}^{a}} \frac{\partial Y_{d}^{c} \partial Y_{b}^{a}}{\partial Y_{J}^{I} \partial Y_{L}^{K}}+\frac{\partial^{2} U_{F}}{\partial Y_{d}^{c} \partial Y_{d}^{c}} \frac{\partial Y_{d}^{c} \partial Y_{d}^{c}}{\partial Y_{J}^{I} \partial Y_{L}^{K}}$

A Expressão (3.50), resulta em uma matriz quadrada de ordem 3(GPA+1), onde GPA é o grau de aproximação adotado para os polinômios das fibras, e para acoplar esta matriz à matriz do contínuo, se adota antes uma estratégia de expansão da mesma.

$\left[H_{E}^{F}\right]_{3 N T(G P A+1) \times 3 N T(G P A+1)}=[\Phi]_{3 N T(G P A+1) \times 3(G P A+1)} \cdot\left[H^{F}\right]_{3(G P A+1) \times 3(G P A+1)}[\Phi]_{3(G P A+1) \times 3 N T(G P A+1)}$

Sendo NT o número de nós do tetraedro, $\left[\mathrm{H}^{\mathrm{F}}\right]$ a matriz hessiana das fibras, $\left[\mathrm{H}_{\mathrm{E}}^{\mathrm{F}}\right]$ a matriz hessiana das fibras expandidas e $[\Phi]$ a matriz das funções de forma expandida.

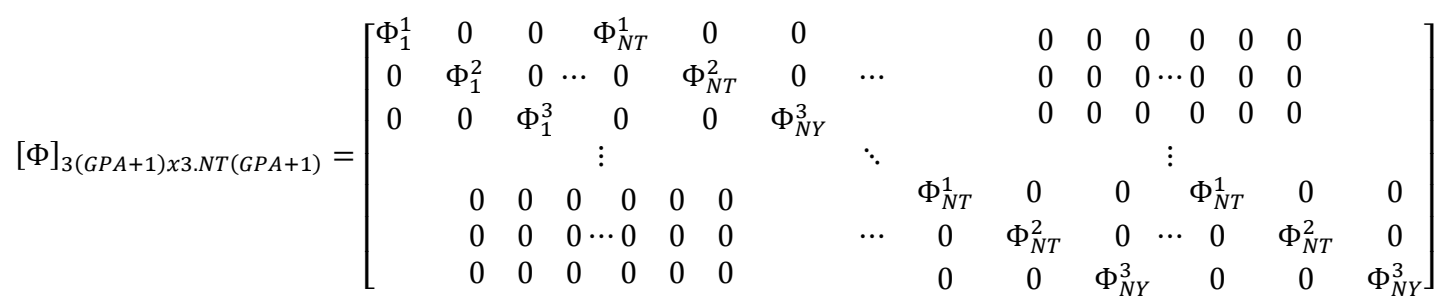

Para se obter a matriz citada na Equação (3.52) é necessário conhecer as coordenadas adimensionais $\xi$ das fibras em termos dos nós do sólido. Isto é possível pela resolução de um processo iterativo de varredura (VANALLI, 2004; VANALLI; PACCOLA; CODA, 2008).

Parte-se da ideia de que se pode descrever o nó da fibra em função dos nós da matriz:

$X_{\text {fibra }}^{i}=\Phi_{l}\left(\xi_{1}^{f}, \xi_{2}^{f}, \xi_{3}^{f}\right) X_{l}^{i}$ 
Sendo $X_{l}^{i}$ as coordenadas reais dos nós da matriz, $X_{\text {fibra }}^{i}$ as coordenadas reais dos nós das fibras, $\Phi_{l}$ as funções de formas do sólido e $\xi$ as coordenadas adimensionais das fibras e incógnitas do problema. A Equação (3.53) pode ser expandida em série de Taylor, e truncada:

$X_{\text {fibra }}^{i}=\Phi_{l}\left(\xi_{1}^{t}, \xi_{2}^{t}, \xi_{3}^{t}\right) X_{l}^{i}=\Phi\left(\xi_{1}^{t}, \xi_{2}^{t}, \xi_{3}^{t}\right) X_{l}^{i}+\left.\frac{\Phi\left(\xi_{1}^{t}, \xi_{2}^{t}, \xi_{3}^{t}\right) X_{l}^{i}}{\partial \xi_{j}^{f}}\right|_{\xi_{1}^{t}, \xi_{2}^{t}, \xi_{3}^{t}} \Delta \xi_{j}$

Sendo $\xi_{1}^{t}, \xi_{2}^{t}, \xi_{3}^{t}$ as coordenadas tentativas do problema, tem-se o sistema de equações resultante.

$X_{i}^{\text {fibra }}=X_{i}^{\text {ftentativa }}+C_{i j} \Delta \xi_{j}$

A correção $\Delta \xi_{j}$ é obtida resolvendo o sistema apresentado na Equação (3.55), que pode ser não linear, cujo critério de parada, se adotado como, é a comparação do valor da norma do vetor $\Delta \xi_{j}$ com uma tolerância pré-estabelecida.

A partir daí pode-se também determinar as coordenadas atuais dos nós das fibras, garantindo assim a perfeita aderência entre a fibra e a matriz.

$Y_{\text {fibra }}^{i}=\Phi_{l}\left(\xi_{1}^{f}, \xi_{2}^{f}, \xi_{3}^{f}\right) Y_{l}^{i}$ 


\section{EXEMPLOS DE APLICAÇÃO}

Neste capítulo são apresentados 05 exemplos de aplicação da formulação implementada com o objetivo de validar e apresentar as potencialidades da referida formulação.

A formulação do elemento finito posicional tetraédrico, como dito anteriormente, segue a ideia apresentada em Maciel (2008). Neste sentido, para validar a formulação de elementos finitos sólidos, são apresentados os dois primeiros exemplos, sugeridos por Maciel (2008). O primeiro exemplo trata-se de viga engastada e livre, submetida a um carregamento concentrado na extremidade livre. Para este exemplo, os resultados analíticos podem ser encontrados em Mattiasson (1981). O segundo exemplo trata de uma coluna engastada e livre, submetida a uma força concentrada de compressão na extremidade livre buscando representar o comportamento da flambagem elástica de Euler. Os resultados são confrontados com o valor da carga crítica para o primeiro modo de flambagem.

No que se refere ao reforço com fibras, a formulação da presente pesquisa, também como dito anteriormente, se baseia nos trabalhos de Vanalli (2004), Sampaio, Paccola e Coda (2013) e Sampaio (2014). Assim, os exemplos 3 e 4 deste capítulo foram extraídos do trabalho de Sampaio (2014) com a finalidade de validar a formulação de elementos finitos sólidos reforçados com fibras, ou seja, verificar o comportamento acoplado dos elementos finitos tetraédricos e de barra simples. O terceiro exemplo simula o comportamento de uma viga engastada e livre, reforçada com 4 barras ao longo do comprimento e submetida a um carregamento uniformemente distribuído na face superior. Os resultados em deslocamentos são comparados com os resultados apresentados em Sampaio (2014) para a extremidade livre da viga. O quarto exemplo trata-se uma placa quadrada, simplesmente apoiada e submetida a um carregamento uniformemente distribuído. Novamente, os resultados em deslocamentos são comparados com os resultados apresentados em Sampaio (2014) para o centro da placa. 
Finalmente, o quinto exemplo apresenta as potencialidades da formulação no que se refere à utilização de fibras curtas distribuídas aleatoriamente no contínuo. Apresentam-se os resultados de deslocamentos para uma viga bi-apoiada e submetida a um carregamento uniformemente distribuído na face superior. São colocadas fissuras ao longo do comprimento da viga para averiguar a real contribuição das fibras na rigidez do conjunto.

A formulação apresentada nos capítulos anteriores permite o desenvolvimento de elementos finitos de ordem qualquer tanto para o sólido quanto para a fibra. No entanto, desenvolvimentos recentes do grupo de pesquisa no qual este trabalho se insere mostram que, no que se referem à obtenção dos campos de tensões e deslocamentos, aproximação cúbica para a matriz e linear para a fibra são suficientes para uma boa representação desses campos (PACCOLA; SAMPAIO; CODA, 2015). Portanto, em todos os exemplos foram utilizados elementos tetraédrico cúbicos para modelagem da matriz e elementos de barra simples lineares para modelagem do reforço. As malhas de elementos tetraédricos foram geradas com aproximação linear no programa comercial Ansys ${ }^{\circledR}$ e posteriormente adaptadas para inclusão dos nós necessários para consideração de aproximação cúbica de posições. Os resultados são apresentados fazendo-se uso do programa de pós-processamento AcadView (PACCOLA, R. R.; CODA, H. B, 2005).

\subsection{EXEMPLO 1: VIGA ENGASTADA SUBMETIDA A CARREGAMENTO CONCENTRADO}

Este primeiro exemplo apresenta a análise de uma viga engastada e livre, submetida a um carregamento concentrado na extremidade livre, tal como apresentado na Figura 11. A viga tem comprimento $\mathrm{L}=10 \mathrm{~m}$ e seção transversal quadrada, com área de $2,391 \times 10^{-3} \mathrm{~m}^{2} \mathrm{e}$ momento de inércia $4,764 \times 10^{-7} \mathrm{~m}^{4}$. O material adotado na modelagem da viga tem módulo de elasticidade $210 \mathrm{GPa}$ e $v=0,0$. O carregamento foi aplicado em 20 passos.

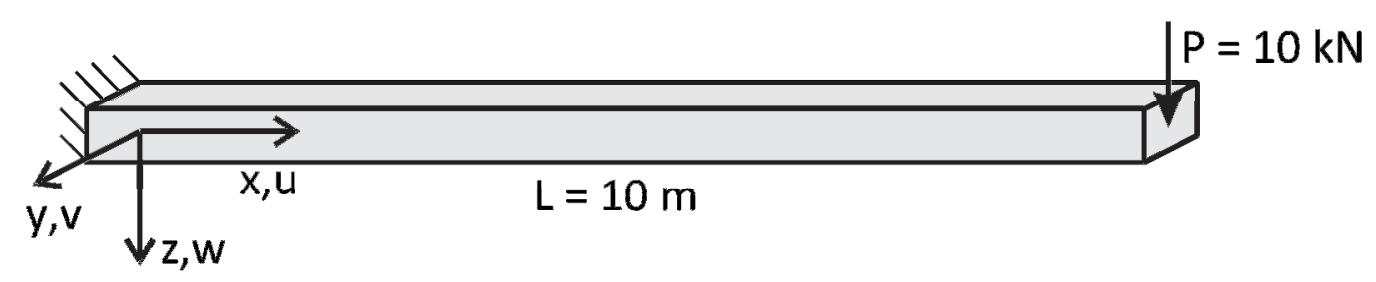

Figura 11: Geometria e condições de contorno do Exemplo 01 
Os resultados de deslocamentos u e w, nas direções $\mathrm{x}$ e $\mathrm{z}$, respectivamente, foram obtidos para o ponto de aplicação da carga considerando 3 malhas diferentes, buscando com isso uma análise de convergência para os resultados. Os resultados de tal análise são apresentados na Figura 12.

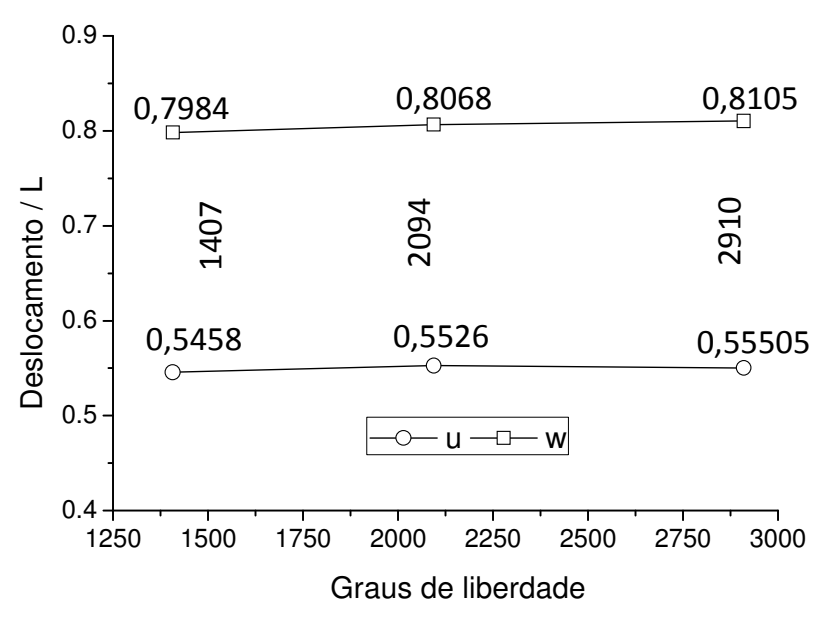

Figura 12: Análise de convergência: deslocamentos u e w na extremidade livre da viga para 3 malhas diferentes

Assumindo que a malha com 2.910 graus de liberdade foi a malha que convergiu, com base nos resultados apresentados na Figura 12, adotou-se esta malha para comparação dos resultados numéricos com os resultados analíticos apresentados em Mattiasson (1981). As comparações dos valores de deslocamentos na extremidade livre da viga, nas direções x (u) e z (w), para diferentes níveis de carregamento, são apresentadas, respectivamente, nas Figuras 13 e 14.

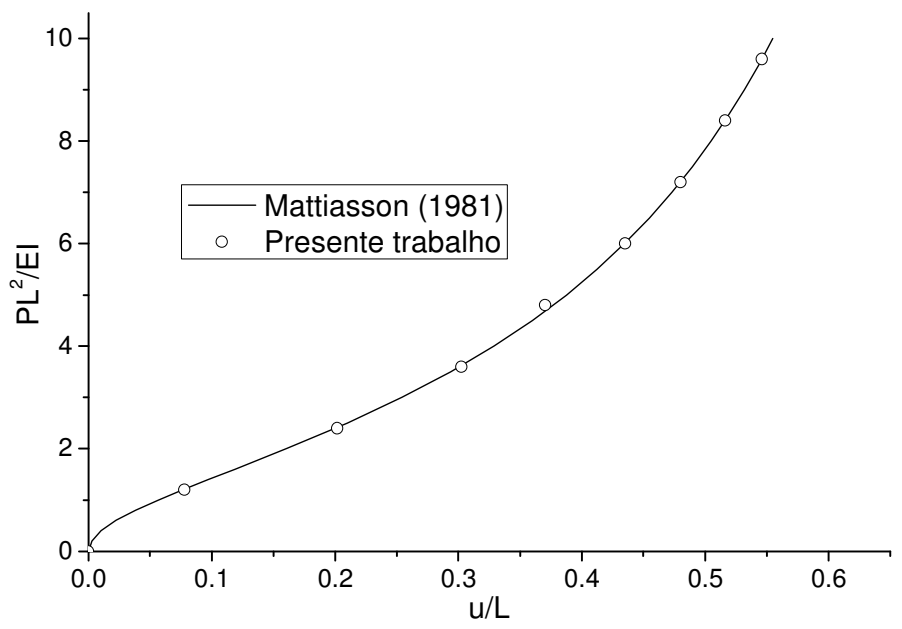

Figura 13: Deslocamento da extremidade livre da viga na direção x (u) para diferentes níveis de carga. 


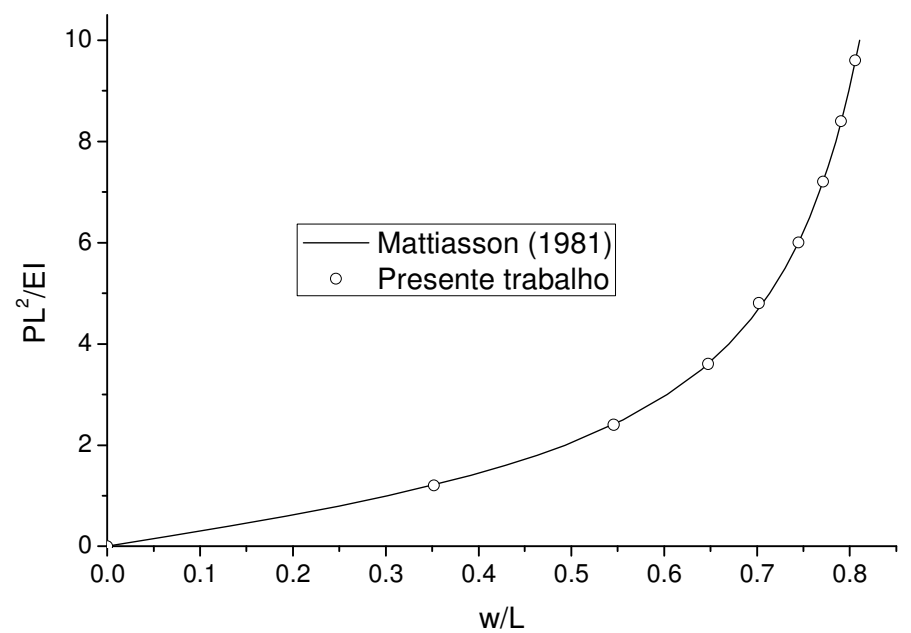

Figura 14: Deslocamento da extremidade livre da viga na direção z (w) para diferentes níveis de carga.

A concordância observada nas Figuras 13 e 14 entre os valores analítico (MATITIASSON,1981) e os obtidos na presente pesquisa validam as implementações do elemento finito tetraédrico para grandes deslocamentos. Vale lembrar que as soluções analíticas apresentadas em Mattiasson (1981) foram obtidas para o caso de problemas de grandes deslocamentos em pórticos planos.

A Figura 15 apresenta a configuração deslocada da viga para diferentes níveis de carga, dentro do total de 20 passos aplicados.

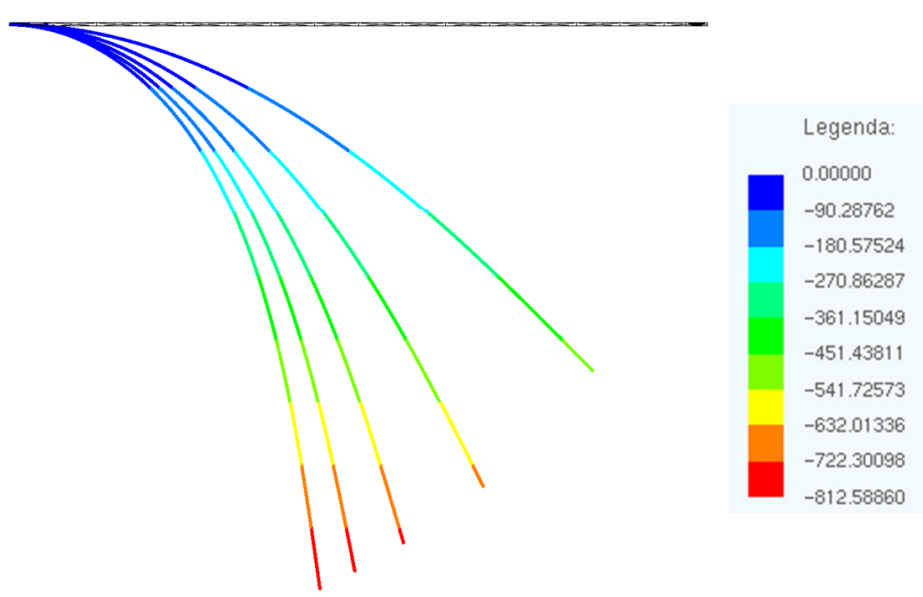

Figura 15: Deslocamento na direção z (w) em centímetros para diferentes níveis de carga. 


\subsection{EXEMPLO 2: FLAMBAGEM ELÁSTICA DE EULER}

Este exemplo apresenta o comportamento de uma coluna engastada e livre, Figura 16, submetida a uma força concentrada de compressão na extremidade livre, buscando-se representar a instabilidade inerente ao problema, conhecido na literatura como flambagem elástica de Euler. A coluna possui seção transversal quadrada, com comprimento $\mathrm{L}=2 \mathrm{~m}$, área de $1,75 \times 10^{-2} \mathrm{~m}^{2}$ e momento de inércia $2,552 \times 10^{-5} \mathrm{~m}^{4}$. $\mathrm{O}$ material adotado na modelagem da coluna tem módulo de elasticidade $210 \mathrm{GPa}$ e $\nu=0,0$. O carregamento foi aplicado em 100 passos. Os resultados são confrontados com o valor da carga crítica para o primeiro modo de flambagem. Neste caso, a carga crítica é dada por $P_{c r}=\left(E I \pi^{2}\right) / L_{f}{ }^{2}$, sendo o comprimento de flambagem para a configuração de vinculação apresentada na Figura 15 é $L_{f}=2 \mathrm{~L}$. Assim, o valor da carga crítica é $P_{c r}=3.305,82 \mathrm{kN}$. Adotou-se uma defasagem (defeito) de L/1000 entre as seções engastada e livre de tal forma a se garantir a perda de estabilidade em primeiro modo.

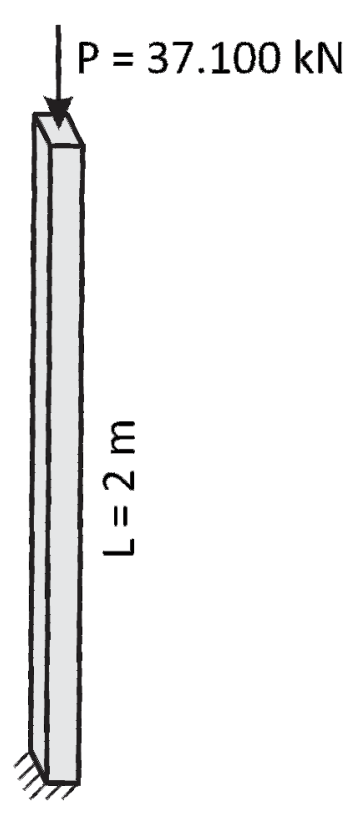

Figura 16: Geometria e condições de contorno do Exemplo 02

A malha de elementos tetraédricos de aproximação cúbica é composta por 415 nós e 60 elementos, totalizando 1.245 graus de liberdade. Os valores de deslocamento lateral na extremidade livre para os diferentes níveis de carga são apresentados na Figura 17, representando a trajetória de equilíbrio para o referido ponto. Apresenta-se na mesma figura 
uma linha horizontal correspondente ao valor da carga crítica de flambagem. Observa-se que a perda de estabilidade verificada na Figura 17 corresponde ao valor da carga crítica calculada.

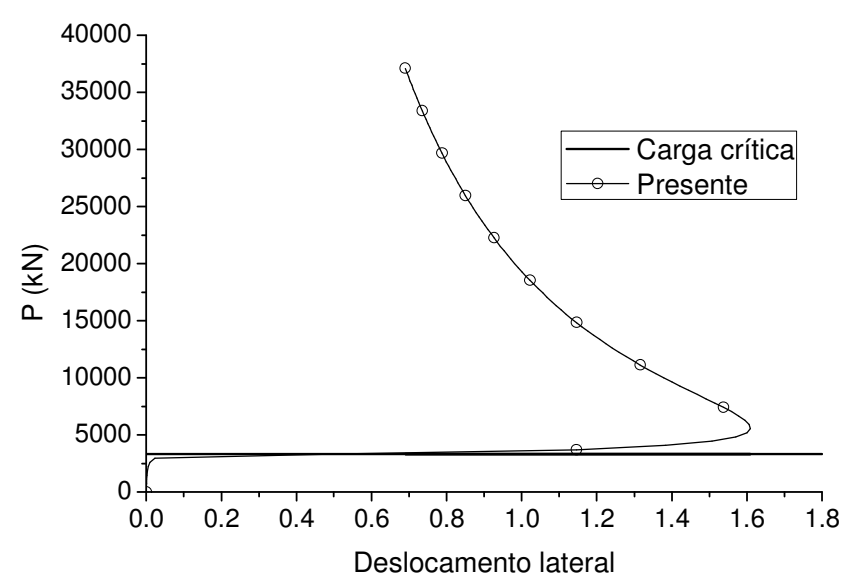

Figura 17: Deslocamento lateral e metros na extremidade livre para diferentes níveis de carga

A Figura 18 apresenta a configuração deslocada e mapa de cores de deslocamento lateral para diferentes níveis de carga. Nota-se que a perda de estabilidade ocorreu entre os níveis $8 \%(2.968 \mathrm{kN})$ e $9 \%(3.339 \mathrm{kN})$ de carga como esperado, uma vez que a carga crítica determinada para o problema corresponde a 8,91\% $(3305,82 \mathrm{kN})$ da carga total de $37.100 \mathrm{kN}$.

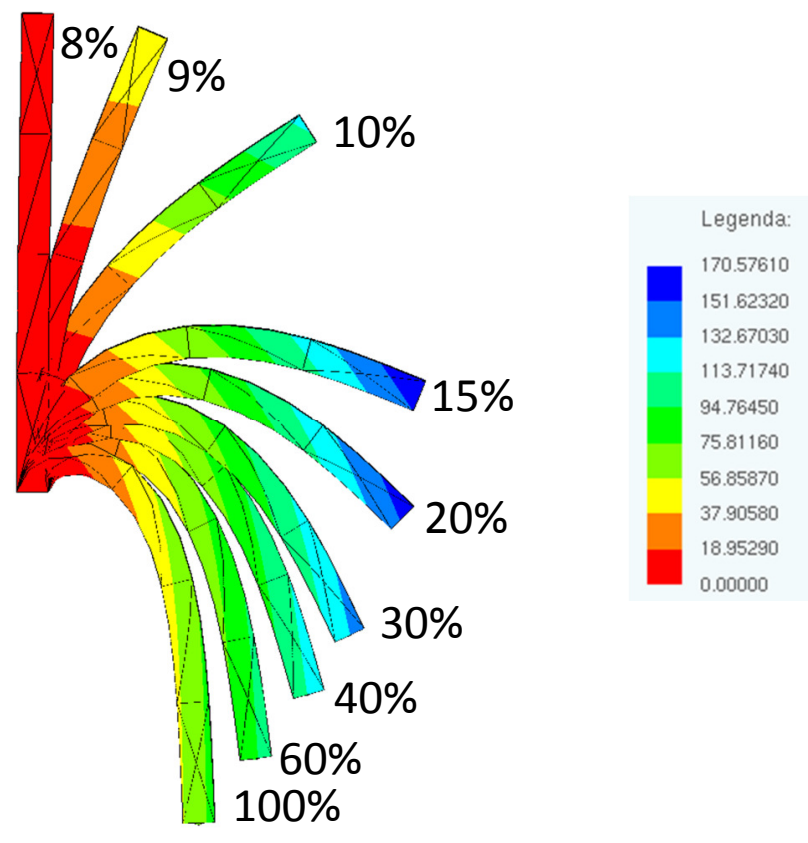

Figura 18: Configuração deslocada e mapa de cores de deslocamento lateral em centímetros para diferentes níveis de carga 


\subsection{EXEMPLO 3: VIGA REFORÇADA ENGASTADA SUBMETIDA A CARREGAMENTO DISTRIBUÍDO}

Este terceiro exemplo simula o comportamento de uma viga engastada e livre, reforçada com 4 barras ao longo do comprimento e submetida a um carregamento uniformemente distribuído na face superior $\mathrm{q}=25 \mathrm{MN} / \mathrm{m}^{2}$. A viga tem comprimento $\mathrm{L}=3 \mathrm{~m}$ e seção transversal $\mathrm{b}=0,20 \mathrm{~m}$ e $\mathrm{h}=0,60 \mathrm{~m}$, Figura 19 . O material adotado para a matriz possui módulo de elasticidade $21 \mathrm{GPa}$ e $v=0,0$. As barras de reforço possuem módulo de elasticidade $210 \mathrm{GPa}$ e área de seção transversal de $2 \times 10^{-4} \mathrm{~m}^{2}$. O carregamento foi aplicado em 20 passos. O cobrimento "c" adotado para as barras de reforço é de 3,8 cm.

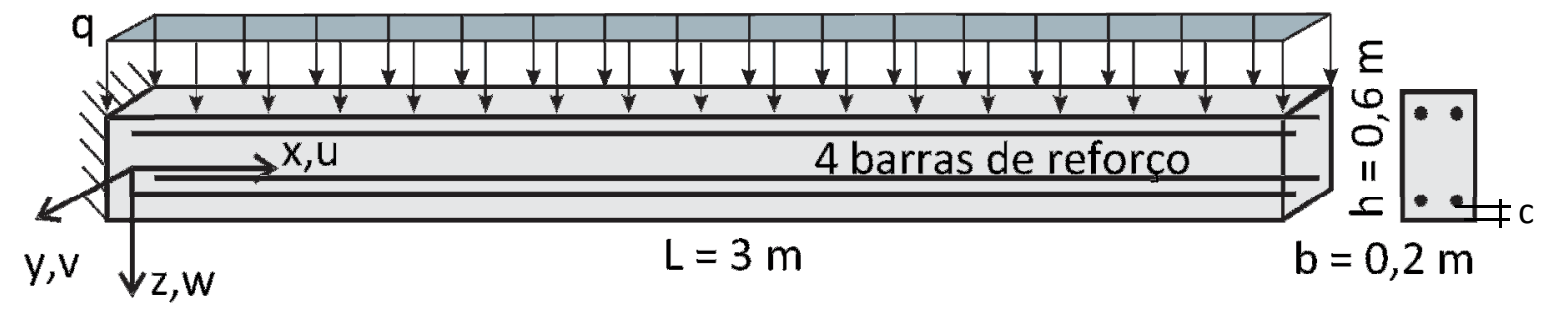

Figura 19: Geometria e condições de contorno do Exemplo 03

A malha de elementos tetraédricos de aproximação cúbica, para simular o comportamento da matriz, é composta por 23.401 nós e 4.278 elementos, totalizando 70.203 graus de liberdade. Cada uma das 04 barras de reforço foi modelada com 201 nós e 200 elementos finitos de barra simples com aproximação linear, totalizando 804 nós e 800 elementos, vale lembrar que os graus de liberdade das fibras não aumentam o número de graus de liberdade do problema.

Os resultados em deslocamentos são comparados com os resultados apresentados em Sampaio (2014) para a extremidade livre da viga, considerando 4 diferentes formulações: (a) barra geral 3D com cinemática de Reissner-Timoshenko, Coda (2009); (b) sólido bidimensional reforçado com fibras, Sampaio, Paccola e Coda (2013); (c) cascas laminadas, Coda, Paccola e Sampaio (2013) e (d) cascas reforçadas com fibras, Sampaio (2014). A Tabela 02 apresenta os valores de deslocamento máximo obtido na extremidade livre da viga, na direção z (w), para o presente trabalho e para as quatro diferentes formulações citadas. 
Tabela 02: Valores de deslocamento na direção z para a extremidade livre $(\mathrm{cm})$

(a)

(b)

(c)

(d)

Presente

57,894

62,949

58,472

57,917

63,292

Os resultados apresentados na Tabela 02 confirmam o bom desempenho da formulação para problemas acoplados considerando grandes deslocamentos. As diferenças encontradas entre as formulações são justificadas pelas particularidades de modelagem adotadas em cada uma delas. Como era esperado, o modelo sólido da presente pesquisa se mostrou mais flexível que os demais, uma vez que a representação do problema é mais adequada com este tipo de formulação, onde não se aproximam deslocamentos relativos ao longo da espessura por um valor de rotação na seção transversal, ou seja, não são impostas condições cinemáticas através de hipóteses simplificadoras.

A Figura 20 apresenta a configuração final deslocada da viga reforçada. As barras de reforço são apresentadas separadamente da matriz e associadas à malha de tetraedros na configuração inicial indeformada.
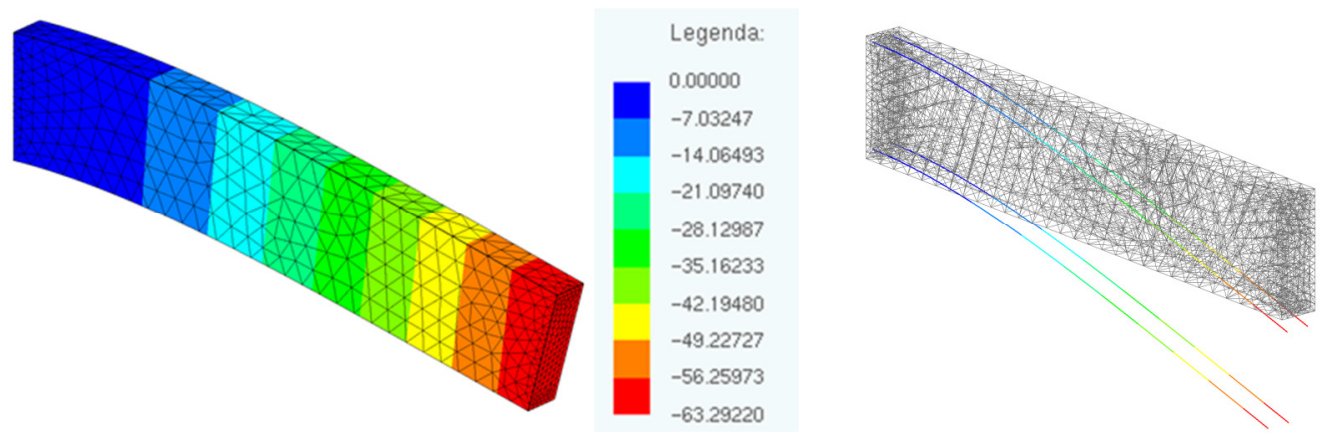

Figura 20: Configuração deslocada e mapa de cores de deslocamento na direção z (w) em centímetros.

\subsection{EXEMPLO 4: PLACA REFORÇADA SIMPLESMENTE APOIADA}

Neste exemplo apresenta-se o comportamento de uma placa quadrada, simplesmente apoiada e submetida a um carregamento uniformemente distribuído. A placa foi analisada primeiramente sem reforço e posteriormente com duas configurações de distribuição de reforço: unidirecional (fração volumétrica de 1,25\%) e bidirecional (fração volumétrica de 
2,50\%). Novamente, os resultados em deslocamentos são comparados com os resultados apresentados em Sampaio (2014) para o centro da placa, onde os valores foram obtidos utilizando-se formulação de casca com camada homogênea e com barras de reforço discretas. Apenas 1/4 da placa foi analisado em função da dupla simetria do problema. A condição de vinculação foi aplicada nos nós correspondentes à superfície média da placa para o problema tridimensional analisado, tal como se faz tradicionalmente nas formulações de placa e casca.

A placa possui lado $\mathrm{L}=4 \mathrm{~m}$ e espessura $\mathrm{h}=0,16 \mathrm{~m}$. O material adotado na modelagem da placa tem módulo de elasticidade $21 \mathrm{GPa}$ e $v=0,25$. Para o reforço, o módulo de elasticidade adotado é de $210 \mathrm{GPa}$, sendo barras com área de seção transversal de $2 \mathrm{~cm}^{2}$. O carregamento uniformemente distribuído de $\mathrm{q}=1 \mathrm{kN} / \mathrm{m}^{2}$ foi aplicado na face superior da placa em um único passo. A Figura 21 apresenta a geometria e distribuição do reforço para os casos analisados.
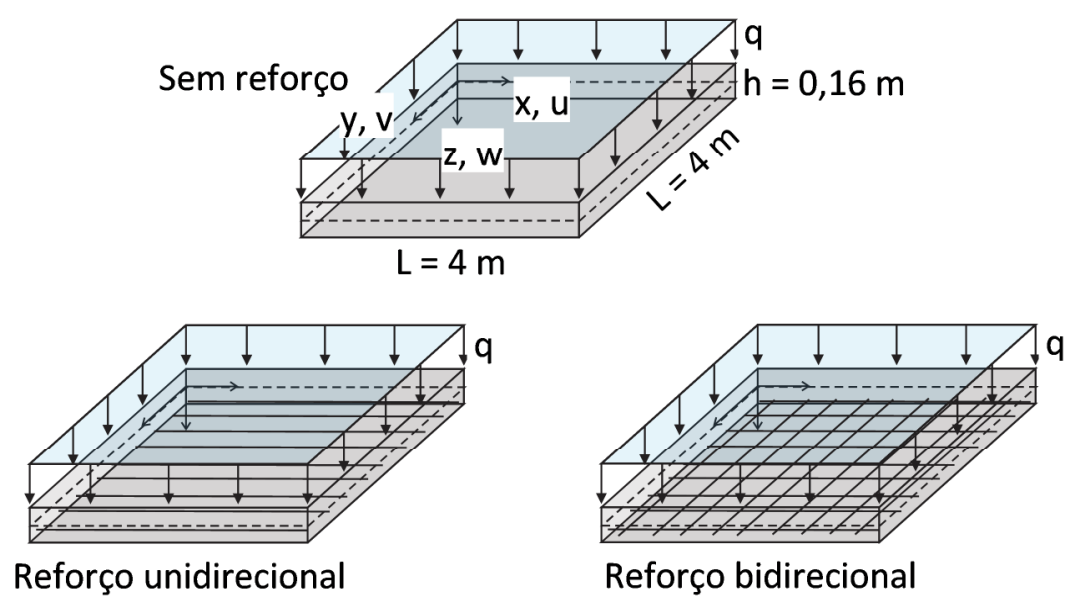

Figura 21: Geometria e distribuição do reforço

A malha de elementos tetraédricos de aproximação cúbica é composta por 11.556 nós e 1.877 elementos, totalizando 34.668 graus de liberdade. Para o caso de reforço unidirecional foram utilizadas 20 barras de reforço igualmente espaçadas, discretizadas num total de 620 nós e 600 elementos. No caso do reforço bidirecional, repetiu-se a discretização para o caso unidirecional para as duas direções que formam a malha de reforço, totalizando 40 barras, 1.240 nós e 1200 elementos. O elemento finito utilizado na discretização do reforço é o de barra simples com aproximação linear. Vale lembrar novamente que os graus de liberdade das fibras não aumentam o número de graus de liberdade do problema.

Os resultados em deslocamentos são comparados com os resultados apresentados em Sampaio (2014) para o centro da placa, tanto para o caso de lâmina equivalente quanto para o caso de laminado reforçado com fibras. A Tabela 03 apresenta os valores de deslocamento 
máximo obtido no centro da placa, na direção z (w), para o presente trabalho e obtidos em Sampaio (2014).

Tabela 03: Valores de deslocamento na direção z para o centro da placa $(\mathrm{cm})$

\begin{tabular}{cccc}
\hline \hline \multirow{2}{*}{ Placa Homogênea } & \multicolumn{2}{c}{ Sampaio (2014) } & 0,0141 \\
\cline { 2 - 4 } & \multicolumn{2}{c}{ Presente trabalho } & 0,0142 \\
\hline \multirow{3}{*}{ Reforço unidirecional } & Sampaio (2014) & lâmina equivalente & 0,0127 \\
\cline { 2 - 4 } & & reforço com fibras & 0,0135 \\
\cline { 2 - 4 } & \multirow{2}{*}{ Reforço bidirecional } & 0,0136 \\
\cline { 2 - 4 } & \multirow{2}{*}{ Sampaio (2014) } & Presente trabalho & 0,0122 \\
\cline { 2 - 4 } & & reforço com fibras & 0,0129 \\
\cline { 2 - 4 } & \multicolumn{2}{c}{ Presente trabalho } & 0,0130 \\
\hline
\end{tabular}

Os resultados apresentados na Tabela 03 confirmam o bom desempenho da formulação para problemas acoplados, validando assim a formulação implementada. Novamente, as diferenças encontradas entre as formulações são justificadas pelas particularidades de modelagem adotadas em cada uma delas.

A Figura 22 apresenta a configuração final deslocada da placa para os 3 casos analisados na presente pesquisa. As barras de reforço são apresentadas separadamente da matriz permitindo a visualização das mesmas na configuração deslocada.

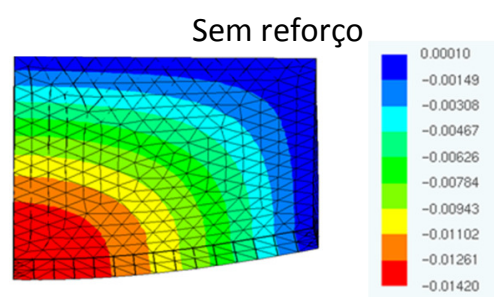

Reforço unidirecional

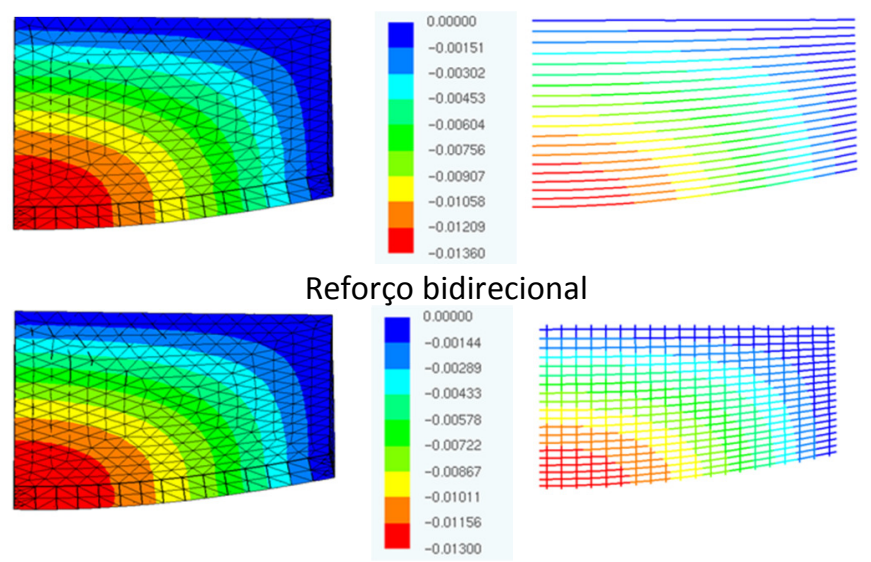

Figura 22: Configuração deslocada e mapa de cores de deslocamento transversal, direção z (w) (cm). 


\subsection{EXEMPLO 5: VIGA REFORÇADA COM FIBRAS CURTAS ALEATÓRIAS}

Este último exemplo foi proposto para demonstrar a potencialidade da formulação no que se refere à utilização de fibras curtas distribuídas aleatoriamente no contínuo. Apresentase o comportamento de uma viga bi-apoiada e submetida a um carregamento uniformemente distribuído na face superior da viga. São introduzidas 7 fissuras igualmente espaçadas e distribuídas ao longo do comprimento da viga para averiguar a real contribuição das fibras na rigidez do conjunto, Figura 23. Cada fissura, com espessura de $0,1 \mathrm{~cm}$, se estende por toda a largura (b) da viga e, partindo da face inferior, atinge 2/3 da altura (h) da mesma. A imposição de deslocamentos nulos nas 3 direções foi aplicada nos nós das extremidades da viga, posicionados ao longo da largura $b$ e na face superior. A viga foi analisada primeiramente sem reforço e posteriormente com uma fração volumétrica de $1,25 \%$ de fibras curtas aleatoriamente distribuídas ao longo dos $2 / 3$ inferiores de $h$, porção onde se encontram as fissuras. Além disso, foram obtidos também resultados para a viga íntegra e com a distribuição aleatória de fibras curtas, além de outras combinações, podendo-se assim verificar a real influência das fibras no comportamento do conjunto.

A viga possui comprimento $\mathrm{L}=4 \mathrm{~m}$, largura $\mathrm{b}=0,10 \mathrm{~m}$ e altura $\mathrm{h}=0,30 \mathrm{~m}$. O material adotado na modelagem da matriz tem módulo de elasticidade 21 GPa e $v=0,0$. Para as fibras aleatórias, o módulo de elasticidade adotado é de $210 \mathrm{GPa}$, sendo fibras com comprimento de $3 \mathrm{~cm}$ e área de seção transversal de $0,1 \mathrm{~cm}^{2}$. O carregamento uniformemente distribuído $\mathrm{q}=50 \mathrm{MN} / \mathrm{m}^{2}$ foi aplicado na face superior da viga dividido em 5 passos. A Figura 23 apresenta a geometria, distribuição das fissuras e condições de contorno para a viga analisada.

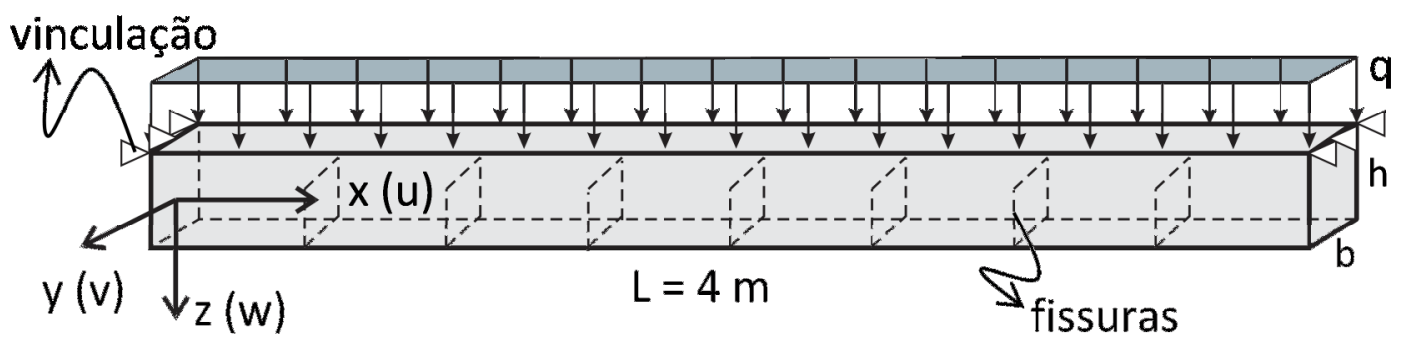

Figura 23: Geometria, fissuras e condições de contorno

A malha de elementos tetraédricos de aproximação cúbica, quando se consideram as fissuras discretizadas, é composta por 9.164 nós e 1.468 elementos, totalizando 27.492 graus 
de liberdade. No caso da viga íntegra, ou seja, sem as fissuras, são 10.171 nós e 1.776 elementos tetraédricos, totalizando 30.513 graus de liberdade. Para as fibras aleatórias, foram utilizados 10.000 nós e 5.000 elementos de barra simples com aproximação linear para representar a fração volumétrica desejada. Vale lembrar novamente que os graus de liberdade das fibras não aumentam o número de graus de liberdade do problema. Do total de 5.000 fibras curtas distribuídas, apenas 168 efetivamente interceptam as fissuras. Neste sentido, foram processadas análises onde apenas as referidas 168 fibras são levadas em consideração, bem como onde estas foram desconsideradas e levadas em conta apenas as fibras posicionadas inteiramente no domínio.

A Tabela 04 apresenta as combinações entre fibras e fissuras consideradas nos 6 modelos analisados, bem como o máximo deslocamento na direção z (w) obtido em cada um desses modelos.

Tabela 04: Modelos analisados: fissuras, fibras e deslocamentos máximos

\begin{tabular}{|c|c|c|c|c|c|c|}
\hline $\begin{array}{l}\frac{0}{0} \\
\frac{0}{0} \\
\frac{0}{2}\end{array}$ & : & 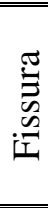 & 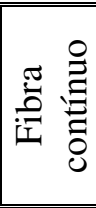 & 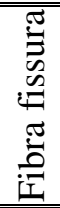 & $\underbrace{\text { ह્తి }}_{3}$ & Discretização: Contínuo e fibras \\
\hline 1 & $\mathrm{~S}$ & $\mathrm{~N}$ & $\mathrm{~N}$ & $\mathrm{~N}$ & 10,9933 & 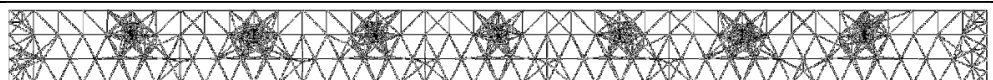 \\
\hline 2 & $\mathrm{~S}$ & $\mathrm{~N}$ & $\mathrm{~S}$ & $\mathrm{~S}$ & 10,6704 & (1) \\
\hline 3 & $\mathrm{~N}$ & $\mathrm{~S}$ & $\mathrm{~N}$ & $\mathrm{~N}$ & 23,8126 & $4 \times 1 \times 1 \times$ \\
\hline 4 & $\mathrm{~N}$ & $\mathrm{~S}$ & $S$ & $S$ & 13,8332 & 17) \\
\hline 5 & $\mathrm{~N}$ & $\mathrm{~S}$ & $S$ & $\mathrm{~N}$ & 23,6846 & 1.1. \\
\hline 6 & $\mathrm{~N}$ & $\mathrm{~S}$ & $\mathrm{~N}$ & $S$ & 14,0617 & A \\
\hline
\end{tabular}

Nos modelos 1 e 2 as fissuras não são consideradas, sendo que a diferença entre esses modelos é a consideração das 5.000 fibras distribuídas aleatoriamente para o modelo 2, justificando um menor deslocamento para este, Tabela 04. Embora tenha sido menor o deslocamento, os resultados mostram que para a viga sem fissuras, a contribuição das fibras é muito pequena em virtude dos valores adotados de módulo de elasticidade para as duas fases e da área das fibras.

Nos modelos 3, 4, 5 e 6 as fissuras foram consideradas na modelagem. O modelo 3 não considera a contribuição das fibras aleatórias, obtendo-se para este caso, como era 
esperado, o maior deslocamento dentre os casos analisados. Já o modelo 4 considera a contribuição das 5.000 fibras distribuídas ao longo de toda a viga. O modelo 5 considera apenas a contribuição das 4.832 fibras posicionadas inteiramente no domínio e o modelo 6 considera apenas a contribuição das 168 fibras que efetivamente interceptam as fissuras.

Os resultados apresentados na Tabela 04 para os modelos 3 e 5 corroboram a conclusão obtida da comparação entre os modelos 1 e 2, ou seja, a influência das fibras totalmente inseridas no domínio oferecem pouca contribuição para a rigidez do conjunto. Já os modelos 4 e 6 demonstram a eficiência alcançada pela utilização das fibras ligando as faces das fissuras. Os resultados em deslocamentos reduziram significativamente para esses dois modelos, quando comparados aos equivalentes sem fibras interceptando as fissuras. Este fato leva à conclusão de que a utilização de fibras dispersas aleatoriamente no domínio deve realmente contribuir para a diminuição da fissuração nos elementos estruturais.

A Figura 24 apresenta a configuração final deslocada da viga para os 6 casos analisados. É possível observar a real contribuição das fibras nos modelos onde as fissuras são consideradas associadas às fibras posicionadas sobre as mesmas (modelos 4 e 6).

1

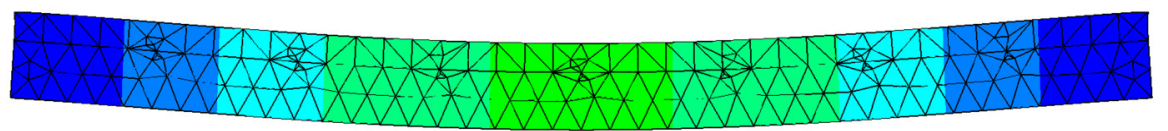

2

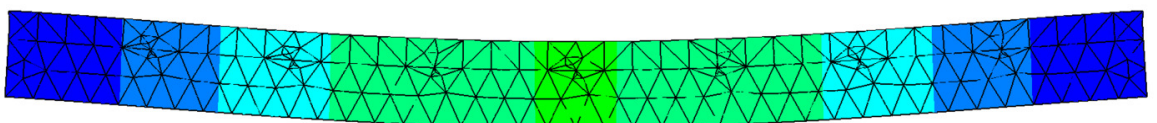

(1)
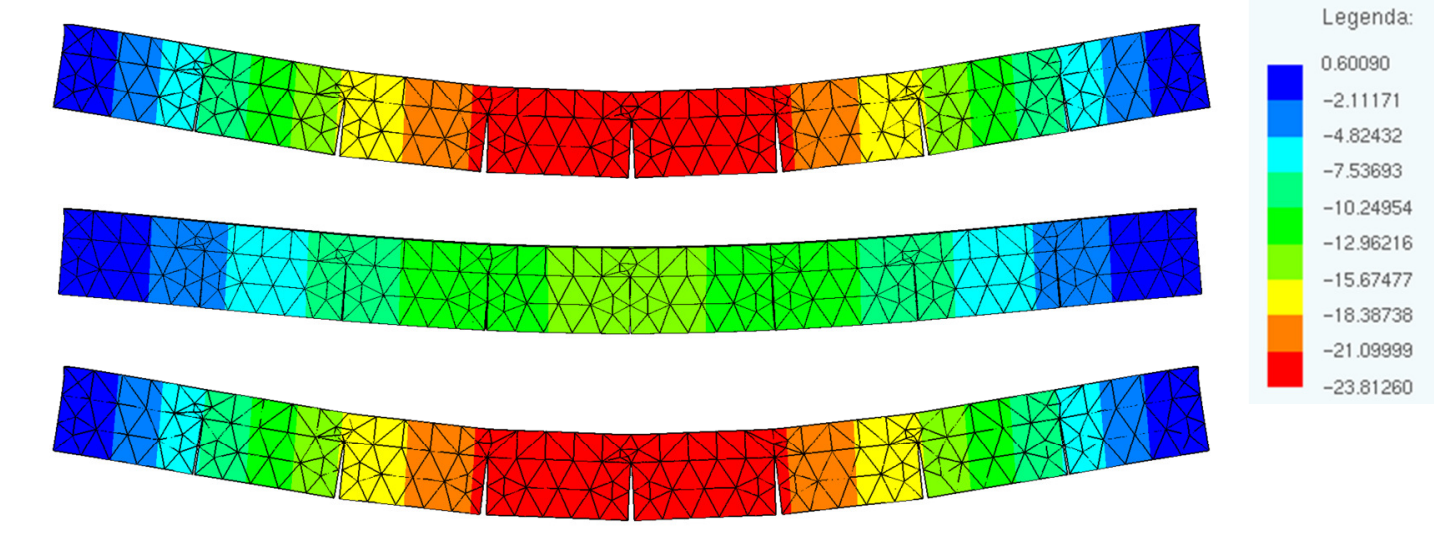

4

6
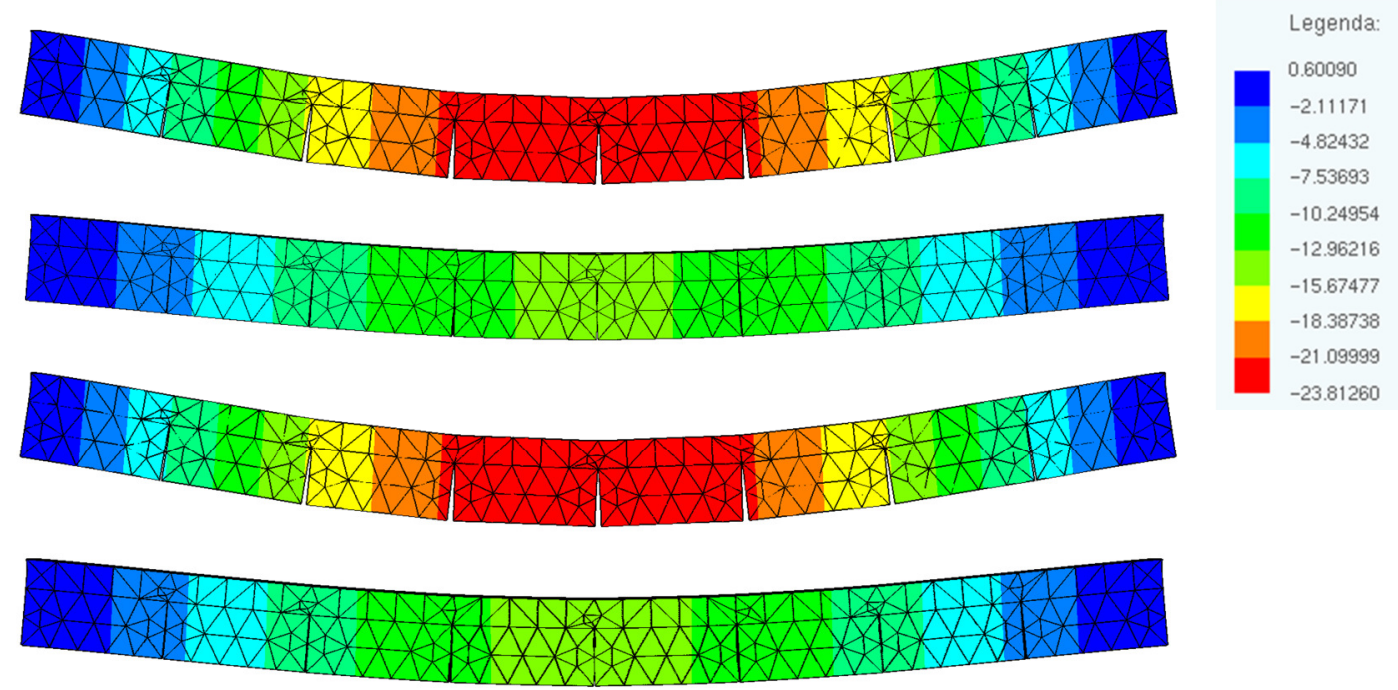

Figura 24: Configuração deslocada e mapa de cores de deslocamento na direção z (w) em centímetros 


\section{CONCLUSÕES}

Neste último capítulo, são apresentadas as conclusões e algumas observações pertinentes em relação aos temas abordados. São feitas sugestões para a continuação da pesquisa e indicação para elaboração de novas pesquisas as quais este trabalho pode servir como base.

\subsection{CONSIDERAÇÕES FINAIS}

O principal objetivo deste trabalho é contribuir no desenvolvimento das formulações elementos finitos posicionais de sólidos tridimensionais reforçados por elementos de fibras curvas para análises de problemas estáticos com não linearidade geométrica. A formulação Posicional, primeiramente apresentada em por Bonet et al (200) e Coda (2003), tem como variáveis do problema as posições nodais ao invés dos deslocamentos.

A formulação Posicional para sólidos reforçados com fibras mostrou resultados satisfatórios ao ser comparado com análises apresentadas na literatura específica, inclusive para estruturas esbeltas, ao mesmo tempo em que se mostrou objetiva e simples na implementação de sua linguagem matemática, principalmente ao se considerar o problema não linear geométrico.

A estratégia de se acoplar os elementos de fibras atrelados aos graus de liberdade do sólido, seguindo a ideia apresentada em Vanalli (2004) e Sampaio (2014), mostrou-se eficaz no sentido de que a consideração do reforço de fibras, seja ele distribuído aleatoriamente ou não no contínuo, não provoca aumento no número de graus de liberdade do sistema. Esta ideia permite analisar um problema de sólido reforçado, com um sistema que contenha o mesmo número de incógnitas de um sistema com apenas o sólido, portanto seria interessante comparar esta resolução com outras no que diz respeito a benefícios quanto ao tempo de processamento. 
Para possibilitar a inclusão das fibras de forma livre, sem coincidência dos nós das fibras com os nós das discretizações da matriz, criou-se algoritmo que identifica a qual elemento finito um ponto qualquer da fibra pertence e quais são as coordenadas adimensionais deste ponto relativas ao elemento finito detectado. Este algoritmo foi testado com sucesso nos três últimos exemplos apresentados no Capítulo 4.

A formulação apresentou bons resultados para grandes deslocamentos, como se observa no Exemplo 1, e até para casos de instabilidade como visto no Exemplo 2. Quando comparados os resultados da formulação tridimensional com resultado de formulações bidimensionais, o presente trabalho se mostrou mais flexível, o que era esperado visto que simplificações matemáticas na cinemática de formulações com dimensões reduzidas enrijecem o domínio.

Os resultados em deslocamentos apresentados no Exemplo 5 do Capítulo 4 levaram também à conclusão de que a utilização de fibras dispersas aleatoriamente no domínio deve realmente contribuir para a diminuição da fissuração nos elementos estruturais, tendo em vista a significativa redução de deslocamento obtida quando da consideração das fibras passando pelas fissuras introduzidas no modelo proposto.

\subsection{PROPOSTA DE TRABALHOS FUTUROS}

Considerando-se a abrangência dos temas que esta pesquisa aborda, como por exemplo, não linearidade geométrica, materiais compósitos, elementos finitos sólidos e de barras, a potencialidade da formulação proposta, como pôde ser observado nos exemplos, sugere-se para trabalhos futuros, os quais esta pesquisa pode servir de base:

- Consideração de não linearidade física na fibra e na matriz;

- Consideração de deslizamento entre fibra e matriz;

- Consideração de distribuição de tensão nas fibras;

- Inclusão de comportamento dinâmico nas fases;

- Paralelização do código devido ao alto custo computacional que problemas de sólido com grandes refinamentos podem causar, além do custo atribuído ao número excessivo de fibras no caso de modelos com fibras curtas aleatoriamente distribuídas. 


\section{REFERÊNCIA BIBLIOGRÁFICA}

ANSYS $^{\circledR}$ Multiphysics, Version 15 [S.1]: ANSYS Inc.

ASSAN, A. E. Método dos elementos finitos: primeiros passos. 2. ed. Campinas: Editora da Unicamp, 2003. 304 p.

BARBONI, M.; BENEDETTI, A.; NANNI, A.. Carbon FRP Strengthening of Doubly Curved Precast PC Shell. J. Compos. Constr., [s.1.], v. 1, n. 4, p.168-174, nov. 1997. American Society of Civil Engineers (ASCE). DOI: 10.1061/(asce)1090-0268(1997)1:4(168).

BARUT, A. et al. A new stiffened shell element for geometrically nonlinear analysis of composite laminates. Computers \& Structures, [s.1.], v. 77, n. 1, p.11-40, jun. 2000. Elsevier BV. DOI: 10.1016/s0045-7949(99)00201-1.

BATHE, K. J. Finite element procedures in engineering analysis. New Jersey: PrenticeHall, Inc., Englewood Cliffs, 1982.

BELYTSCHKO, T. et al. Hourglass control in linear and nonlinear problems. Computer Methods In Applied Mechanics And Engineering, [s.1.], v. 43, n. 3, p.251-276, maio 1984. Elsevier BV. DOI: 10.1016/0045-7825(84)90067-7.

BERNARDI, S.T. Avaliação do Comportamento de Materiais Compósitos de Matrizes cimentícias Reforçadas com Fibras de Aramida Kevlar. 178f. 2003. Dissertação (Mestrado em Engenharia ) - Departamento de Engenharia Civil, Universidade Federal do Rio Grande do Sul,Porto Alegre, 2003. 
BONET, J.; WOOD, R.D.; MAHANET, J.; HEYWOOD, P. Finite element analysis of air supported membrane structures. Comput. Methods Appl. Mech. Eng., 190(5-7), 579595,2000 .

BRESCANSIN, J. Comportamento à Fratura de Compósitos de Matriz Cimentícia Reforçada com Polpa de Bambu. 84f. 2003. Dissertação (Mestrado em Ciência dos Materiais e Metalurgia) - Departamento de Ciência dos Materiais e Metalurgia, Pontifícia Universidade Católica do Rio de Janeiro, Rio de Janeiro, 2003.

CALLISTER,W.D. Fundamentals of Materials Science and Engeneering: An integrate Approach. 2. ed.: John Wiley \& Sons, Inc, 2005.

CARRAZEDO, R.; CODA, H. B. Estudo e desenvolvimento de código computacional para análise de impacto entre estruturas tridimensionais levando em consideração efeitos térmicos. Cadernos de Engenharia de Estruturas (USP), v. 8, p. 161-164, 2006.

CHAN, E. C. Nonlinear geometric, material and time dependent analysis of reinforced concrete shells with edge beams. Berkeley, 1982. $361 \mathrm{f}$. PhD Thesis (Structural Engineering and Structural Mechanics) - University of California.

CIARLET, P. Mathematical Elasticity - Volume 1: Three Dimensional Elasticity. NorthHolland, 1988.

\section{CLAURE, J. D. Análise tridimensional elasto-viscoplastica de estruturas de} concretoatravés do método dos elementos finitos. 145f. 1994. Dissertação (Mestrado em Engenharia de Estruturas) - Departamento de Engenharia Civil, Universidade Federal do Rio Grande do Sul, Porto Alegre, 1994.

CODA, Humberto Breves. An exact FEM geometric non-linear analysis of frames based on position description. In: CONGRESSO BRASILEIRO DE ENGENHARIA MECÂNICA, 17., 2003, São Paulo. Proceedings... . São Paulo: Abcm, 2003. p. 1 - 10.

CODA, H.B. Mecânica dos Materiais e das Estruturas - Notas de Aula. Escola de Engenharia de São Carlos. São Paulo. 2008. 
CODA, H. B.. A solid-like FEM for geometrically non-linear 3D frames. Computer

Methods In Applied Mechanics And Engineering, [s.1.], v. 198, n. 47-48, p.3712-3722, out. 2009. Elsevier BV. DOI: 10.1016/j.cma.2009.08.001.

CODA, H. B.; GRECO, M. A simple FEM formulation for large deflection 2D frame analysis based on position description.Computer Methods In Applied Mechanics And Engineering, [s.1.], v. 193, n. 33-35, p.3541-3557, ago. 2004. Elsevier BV. DOI: 10.1016/j.cma.2004.01.005.

CODA, H. B.; PACCOLA, R. R.. An Alternative Positional FEM Formulation for Geometrically Non-linear Analysis of Shells: Curved Triangular Isoparametric Elements. Computational Mechanics, [s.1.], v. 40, n. 1, p.185-200, 2007. Springer Science + Business Media. DOI: 10.1007/s00466-006-0094-1.

CODA, H. B., PACCOLA, R.R. A positional FEM formulation for geometrical nonlinear analysis of shells. Latin American Journal of Solids and Structures. v.5, p. 205-223, 2008.

CODA, H. B.; PACCOLA, R. R.. Improved finite element for 3D laminate frame analysis including warping for any cross-section. Applied Mathematical Modelling, [s.1.], v. 34, n. 4, p.1107-1137, abr. 2010. Elsevier BV. DOI: 10.1016/j.apm.2009.07.020.

CODA, H. B.; PACCOLA, R. R.. A FEM procedure based on positions and unconstrained vectors applied to non-linear dynamic of 3D frames. Finite Elements In Analysis And Design, [s.1.], v. 47, n. 4, p.319-333, abr. 2011. Elsevier BV. DOI: 10.1016/j.finel.2010.11.001.

CODA, H. B.; PACCOLA, R. R.; SAMPAIO, M. do S. M.. Positional description applied to the solution of geometrically non-linear plates and shells. Finite Elements In Analysis And Design, [s.1.], v. 67, p.66-75, maio 2013. Elsevier BV. DOI: 10.1016/j.finel.2012.12.001.

COIMBRA, A. L. Novas Lições de Mecânica do Contínuo. SÃo Paulo: . Edgard Blucher, 1981. $248 \mathrm{p}$.

COSTA, D. I. G.; ÉDER, L. A.; REIS, A.; et al. Análise Numérica de Falhas em Laminados Usando um Critério Baseado em Fenômenos Físicos. Mecânica Computacional Vol 29, p. $5173-5187,2010$. 
CRISFIELD, M. Non-linear Finite Element Analysis of Solids and Structures. Volume 1: Essentials. John Wiley \& Sons, 1991.362p.

DANIEL, I.; ISHAI, O. Engineering mechanics of composite materials. Oxford University Press Inc., 2006.385p.

DETTMER, W. G.; PERIć, D.. On the coupling between fluid flow and mesh motion in the modelling of fluid-structure interaction. Computational Mechanics, [s.l.], v. 43, n. 1, p.8190, 19 fev. 2008. Springer Science + Business Media. DOI: 10.1007/s00466-008-0254-6.

DONEA, J.; HUERTA, A. Finite element method for flow problems. . Ed. Jhon Wiley \& Sons, 2003.345p.

DUARTE, C. A.; BABUSKA, I.; ODEN, J. T.. Generalized finite element methods for threedimensional structural mechanics problems. Computers \& Structures, [s.1.], v. 77, n. 2, p.215-232, jun. 2000. Elsevier BV. DOI: 10.1016/s0045-7949(99)00211-4.

DWEIB, M. A. et al. All natural composite sandwich beams for structural applications. Composite Structures, [s.1.], v. 63, n. 2, p.147-157, fev. 2004. Elsevier BV. DOI: $10.1016 / \mathrm{s} 0263-8223(03) 00143-0$.

ELWI, A. E.; HRUDEY, T. M.. Finite Element Model for Curved Embedded Reinforcement. J. Eng. Mech., [s.1.], v. 115, n. 4, p.740-754, abr. 1989. American Society of Civil Engineers (ASCE). DOI: 10.1061/(asce)0733-9399(1989)115:4(740).

GAY, D. Composite Materials: Desing and Applications. [S.1.]CRC Press, 2003.599 p.

GRECO, M. Análise de problemas de contato/impacto em estruturas de comportamento não linear geométrica pelo método dos elementos finitos. 2004. 153 p. Tese (Doutorado em Engenharia de Estruturas) - Departamento de Engenharia de Estruturas, Escola de Engenharia de São Carlos, Universidade de São Paulo, São Carlos, 2004.

GRIFFITH, A. A.. The Phenomena of Rupture and Flow in Solids. Philosophical Transactions Of The Royal Society A: Mathematical, Physical and Engineering Sciences, [s.1.], v. 221, n. 582-593, p.163-198, 1 jan. 1921. The Royal Society. DOI: 10.1098/rsta.1921.0006. 
GUIMARÃES, S. S. Utilização de Fibras Vegetais como Reforço para argamassa de Cimento. In: SEMINÁRIO LATINOAMERICANO GLARILEM (GRUPO LATINOAMERICANO DE LA RILEM) SOBRE CONSTRUCCIÓN DE VIVIENDAS ECONÔMICAS, 2., Monterrey, 1982. Anais... Monterrey, 1982. v. 2, p. 181-206.

GUMMADI, L. N. B.; PALAZOTTO, A. N. Nonlinear finite element analysis of beams and ches using parallel processors. Computers \& Structures, v.63, n. 3, p. 413- 428,1997.

HANNANT, D. J. Fibre Cements and Fibre Concrete. 1. Ed. Jhon Wiley \& Sons, 1978. $234 \mathrm{p}$.

HAYES, M. D. et al. Laboratory and Field Testing of Composite Bridge Superstructure. J. Compos. Constr., [s.1.], v. 4, n. 3, p.120-128, ago. 2000. American Society of Civil Engineers (ASCE). DOI: 10.1061/(asce)1090-0268(2000)4:3(120).

HOLZAPFEL, G. A. Nonlinear Solid Mechanics - A Continuum Approach for Engineering. Chichester, England: John Wiley \& Sons Ltd., 2000. 455p.

HULL, D. An Introduction to Composite Materials. Cambridge, UK: Cambridge University Press, 1988. 344p.

HRON, J.; MÁDLÍK, M.. Fluid-structure interaction with applications in biomechanics. Nonlinear Analysis: Real World Applications, [s.1.], v. 8, n. 5, p.1431-1458, 2006. Elsevier BV. DOI: 10.1016/j.nonrwa.2006.05.007.

HSL. A collection of Fortran codes for large scale scientific computation. Disponível em: <http://www.hsl.rl.ac.uk>. Acesso em: Abr.2013

HYER, M. W.; WHITE, S. Stress Analysis of Fiber-reinforced Composite Materials. [S.1.]: WCB McGraw-Hill,1998. 648p.

JACOB, A., "Infrastructure applications set scene at SPI show", Reinforced Plastics, v. 41, p. $40-46,1997$. 
JUVANDES, L. F. P.; MARQUES, A. T.; JOAQUIM, A. F. Materiais compósitos no reforço de estruturas de betão PARTE 1. Publicação de apoio às disciplinas “Materiais Estruturais" e “ Reabilitação de Reforço de Estruturas”. Departamento de Engenharia Civil, Faculdade de Engenharia U.P (FEUP), Universidade do Porto, Porto, 1996.

KARBHARI, V. M.. Rehabilitation and Renewal of Civil Structural Systems with Advanced Composites. In: ADVANCED COMPOSITES IN CIVIL AND STRUCTURAL ENGINEERING SEMINAR, 1., 1998, S.1.. Proceedings... . S.1.: University Of Southern Queensland, 1998.

KHAN, A. S.; HUANG, S. Continuum Theory of Plasticity. New York: John Wiley \& Sons, Inc., 1995. 421p.

LIAO, C.; REDDY, J. N.. Analysis of anisotropic, stiffened composite laminates using a continuum-based shell element. Computers \& Structures, [s.1.], v. 34, n. 6, p.805-815, jan. 1990. Elsevier BV. DOI: 10.1016/0045-7949(90)90351-2.

LUBIN, G.. Handbook of Composites. 2. ed. New York: van Nostrand Reinhold, 1982. $786 \mathrm{p}$.

MACIEL, D. N. Análise de problemas elásticos não lineares geométricos empregando o método dos elementos finitos posicional. 2008,162p. Tese (Doutorado em engenharia de estruturas) Escola de Engenharia de São Carlos, Universidade de São Paulo, São Carlos-SP.

MACIEL, R. M. C. A. Método dos elementos finitos aplicado à análise de sólidos: concepção e implementação. 2013. 157f. Dissertação (Mestrado em Engenharia de Estruturas) - Instituto Superior Técnico, Universidade técnica de Lisboa, Lisboa, 2013.

MACIEL, D. N.; CODA, H. B. Dynamic Positional Finite Element Method Applied to Nonlinear Geometric 3D Solids. Mecánica Computacional, v. 29, p. 4377-4387, 2010.

MADGE, P. Design, Ecology, Technology: A Historiographical Review. In: Journal of Design History. Vol. 6, número 3p.149-166, 1993.

MANZOLI, O. L.; OLIVER, J.; DIAZ, G.; HUESPE, A. E. Three-dimensional analysis of reinforced concrete members via embedded discontinuity finite elements. Ibracon Structures and Materials Journal. v. 1, p.58-83, 2008. 
MARTINELLI, M. Modelagem de situações de punção em lajes de concreto armado através do método dos elementos finitos. 2003. 149 f. Dissertação (Mestrado em Engenharia de Estruturas) - Departamento de Engenharia Civil, Universidade Federal do Rio Grande do Sul, Porto Alegre, 2003.

MATTIASSON, K.. Numerical results from large deflection beam and frame problems analysed by means of elliptic integrals. International Journal For Numerical Methods In Engineering, [s.1.], v. 17, n. 1, p.145-153, jan. 1981. Wiley-Blackwell. DOI: 10.1002/nme.1620170113.

MEDEIROS, D. S. Análise tridimensional da interação solo-estrutura em fundações de concreto armado pelo método dos elementos finitos. 2006. 171f. . Dissertação (Mestrado em Engenharia de Estruturas) - Departamento de Engenharia Civil, Universidade Federal do Rio Grande do Sul, Porto Alegre, 2006.

MENDONÇA, P. T. Materiais compósitos e estruturas sanduiche. [S.l.]: Manole. Brasil, 2005.630p.

MESCHKE, G.; HELNWEIN, P.. Large-strain 3D-analysis of fibre-reinforced composites using rebar elements: hyperelastic formulations for cords. Computational Mechanics, [s.1.], v. 13, n. 4, p.241-254, jul. 1994. Springer Science + Business Media. DOI: $10.1007 / \mathrm{bf00350227.}$

MEIER, U. State-of-the-practice of advanced composite materials in structural engineering in Europe with emphasis on transportation. In: INTERNATIONAL COMPOSITES CONFERENCE, 2., 2000, Sydney. Proceedings... . Sydney: University Of New South Wales, 2000. p. $44-50$.

MONDKAR, D. P.; POWELL, G. H.. Finite element analysis of non-linear static and dynamic response. International Journal For Numerical Methods In Engineering, [s.1.], v. 11, n. 3, p.499-520, 1977. Wiley-Blackwell. DOI: 10.1002/nme.1620110309. 
MOURA, C. A. Aplicação de formulação baseada no Método dos Elementos Finitos Posicional na análise bidimensional elástica de compósitos particulados. 2015. 85p. (Dissertação Mestrado em Engenharia de Estruturas) - Departamento de Engenharia de Estruturas, Escola de Engenharia de São Carlos, Universidade de São Paulo, São Carlos, 2015.

NOGUEIRA, G. V. Formulação de elemento finito posicional para modelagem numérica de póticos planos constituido por compósitos laminados. 2015. 228p. (Dissertação Mestrado em Engenharia de Estruturas) - Departamento de Engenharia de Estruturas, Escola de Engenharia de São Carlos, Universidade de São Paulo, São Carlos, 2015.

OGDEN, R. W. Non-linear elastic deformation. Chichester, Ellis Horwood. Nova Iorque, 1984. 532p.

NOLETO,L.C. Uma abordagem Euleriana-Lagrangeana para simulação de escoamentos turbulentos com fronteiras móveis. 2010. 174p. TESE (Doutorado em Engenharia Mecânica) - Departamento de Engenharia Mecânica, Universidade de Brasilia, Brasilia, 2015.

PACCOLA, R. R. Análise não linear física de placas e cascas anisotrópicas laminadas acopladas ou não com meio contínuo tridimensional viscoelástico através da combinação entre o MEC e o MEF. 2004. 190 f. Tese (Doutorado em Engenharia de Estruturas) Departamento de Engenharia de Estruturas, Escola de Engenharia de São Carlos, Universidade de São Paulo, São Carlos, 2004.

PACCOLA, R. R.; CODA, H. B. AcadView: Software para pós-processamento em elementos finitos 2D e 3D. Versão 1.0. São Carlos: Departamento de Engenharia de Estruturas, Escola de Engenharia de São Carlos, Universidade de São Paulo, 2005. Disponível em: $<$ http://www.set.eesc.usp.br/portal/pt/softwares/27-pesquisa/softwares/157-acadview>, Acesso em: Set.2012

PACCOLA, R. R.; SAMPAIO, M. S. M.; CODA, H. B. Fiber-matrix contact stress analysis for elastic 2D composite solids. Latin American Journal of Solids and Structures, v. 12, p. 583-611, 2015. 
PASCON, J. P. Modelos constitutivos para materiais hiperelásticos: estudo e implementação computacional. 2008. 230p. (Dissertação Mestrado em engenharia de estruturas). São Carlos: Departamento de Engenharia de Estruturas, EESC, USP, 2008.

PASCON, J. P. Sobre modelos constitutivos não lineares para materiais com gradação funcional exibindo grandes deformações: implementação numérica em formulação não linear geométrica. 2012. 480 f. Tese (Doutorado em Engenharia de Estruturas) Departamento de Engenharia de Estruturas, Escola de Engenharia de São Carlos, Universidade de São Paulo, São Carlos, 2012.

PASCON, J. P.; CODA, H. B.. Large deformation analysis of elastoplastic homogeneous materials via high order tetrahedral finite elements. Finite Elements In Analysis And Design, [s.1.], v. 76, p.21-38, nov. 2013. Elsevier BV. DOI: 10.1016/j.finel.2013.08.006.

PAULA, C. F. Estudo das descrições Langragiana e Eulariana na análise não linear geométrica com o emprego do método dos elementos finitos. 1997. 116f. Dissertação (Mestrado em Engenharia de Estruturas) - Departamento de Engenharia de Estruturas, Escola de Engenharia de São Carlos, Universidade de São Paulo, São Carlos, 1997.

PIEDADE NETO, D.; FAGÁ JÚNIOR, R.; PACCOLA, R. R. AcadMesh2D: Software acadêmico para geração de malhas não-estruturadas 2D para modelos de elementos finitos. Versão beta. São Carlos: Departamento de Engenharia de Estruturas, Escola de Engenharia de São Carlos, Universidade de São Paulo, 2012. Disponível em:

$<$ http://www.set.eesc.usp.br/portal/pt/softwares/27-pesquisa/softwares/410-acadmesh>, Acesso em: Abr.2013

PRATES JR., N. P. Um modelo elasto-viscoplastico para análise de peças de concreto estrutural submetidas ao estado plano de tensão, através do método dos elementos finitos. 1992. 130f. Dissertação (Mestrado em Engenharia de Estruturas) - Departamento de Engenharia Civil, Universidade Federal do Rio Grande do Sul, Porto Alegre, 1992.

RIZKALLA, S.. Rehabilitation of Structures and Bridges”. In: INTERNATIONAL COMPOSITES CONFERENCE, 1., 1999, S.1.. Proceedings... . S.1.: University Of New South Wales, 1999. p. 1 - 10. 
RIUL, C. Desenvolvimento de compósitos estruturais de politetrafluoretileno (PTFE) com fibras continuas. 2009. 122f. Tese (Doutorado em Engenharia Mecânica) Departamento de Engenharia Mecânica, Escola de Engenharia de São Carlos, Universidade de São Paulo, São Carlos, 2009.

RYDER, J.F. Reinforcement of cements and gypsum plasters by glass fibres. Science of Ceramics, v.5, p.539-64, 1970.

ROESLER, J.; HARDERS, H.; BÄKER,M. Mechanical Behaviour of Engineering Materials: Metals, Ceramics, Polymers, and Composites, [S.1.]: Springer,2007. 534p.

SAMPAIO, M. S. M. Análise não linear geométrica de cascas laminadas reforçadas com fibras. 2014. $190 \mathrm{f}$. Tese (Doutorado em Engenharia de Estruturas) - Departamento de Engenharia de Estruturas, Escola de Engenharia de São Carlos, Universidade de São Paulo, São Carlos, 2014.

SAMPAIO, M. do M.; PACCOLA, R. R.; CODA, H. B.. Fully adherent fiber-matrix FEM formulation for geometrically nonlinear 2D solid analysis. Finite Elements In Analysis And Design, [s.1.], v. 66, p.12-25, abr. 2013. Elsevier BV. DOI: 10.1016/j.finel.2012.10.003.

SANCHES, R. A. K. Sobre o acoplamento fluido-casca utilizando o Método dos

Elementos Finitos. 2011. 228 f. Tese (Doutorado em Engenharia de Estruturas) Departamento de Engenharia de Estruturas, Escola de Engenharia de São Carlos, Universidade de São Paulo, São Carlos, 2011.

SANCHES, R. A. K.; CODA, H. B.. On fluid-shell coupling using an arbitrary LagrangianEulerian fluid solver coupled to a positional Lagrangian shell solver. Applied Mathematical Modelling, [s.1.], v. 38, n. 14, p.3401-3418, jul. 2014. Elsevier BV. DOI:

10.1016/j.apm.2013.11.025.

SCOPEL, F.; FARIA, L. I. L. Tendências tecnológicas do uso do sisal em compósitos a partir da prospecção em documentos de patentes. Polímeros, vol. 23, n. 4, p. 514-520, 2013. 
SHINYA, A.; LASSILA, L. V. J.; VALLITTU, P. K.. Three-dimensional finite element analysis of posterior fiber reinforced composite fixed partial denture: framework design for pontic. The European Journal Of Prosthodontics And Restorative Dentistry, S.1., v. 17, n. 2, p.78-84, jul. 2009.

SILVA, W. Q. Sobre análise não linear geométrica de edifícios considerando o empenamento dos núcleos estruturais e a interação solo-estrutura. 2014. 186 f. Tese (Doutorado em Engenharia de Estruturas) - Departamento de Engenharia de Estruturas, Escola de Engenharia de São Carlos, Universidade de São Paulo, São Carlos, 2014.

SURANA, K. S. Geometrically non-linear formulation for 2 dimensional curved beam elements. Computer \& structures, v. 27, p. 105-114,1983.

TAUCHERT, T. R. Energy principles in structural mechanics. McGraw Hill Book Company, 1974. 400p.

TITA, V. Análise dinâmica teórica e experimental de vigas fabricadas a partir de materiais compósitos poliméricos reforçados. 1999. 125p. Dissertação (Mestrado em Engenharia Mecânica) - Departamento de Engenharia Mecânica, Escola de Engenharia de São Carlos, Universidade de São Paulo, São Carlos, 1999.

TORRES, I. F. R. Desenvolvimento e aplicação do método dos elementos finitos generalizados em análise tridimensional não-linear de sólidos. 2003. 221f. Tese (Doutorado em Engenharia de Estruturas) - Departamento de Engenharia de Estruturas, Escola de Engenharia de São Carlos, Universidade de São Paulo, São Carlos, 2003.

VALENTE, P. A. L. Juntas mecânicas em materiais compósitos. 2012. 69f. Dissertação (Mestrado em Engenharia Mecânica) - Departamento de Engenharia Mecânica, Instituto Superior de Engenharia de Lisboa, Lisboa, 2012.

VANALLI, L. O MEC e o MEF aplicados à análise de problemas viscoplásticos em meios anisotrópicos e composto. 2004. 194f. Tese (Doutorado). Departamento de Engenharia de Estruturas, Escola de Engenharia de São Carlos, Universidade de São Paulo, São Carlos, 2004. 
VANALLI, L.; PACCOLA, R. R.; CODA, H. B.. A simple way to introduce fibers into FEM models. Communications In Numerical Methods In Engineering, [s.1.], v. 24, n. 7, p.585603, 2008. Wiley-Blackwell. DOI: 10.1002/cnm.983.

VITORETTI, M. M. Análise da iteração solo-estrutura em fundações de concreto armado pelo método dos elementos finitos. 146f. 2003.Dissertação (Mestrado em Engenharia de Estruturas) - Departamento de Engenharia Civil, Universidade Federal do Rio Grande do Sul, Porto Alegre, 2003.

YANG, H.T.Y.; SAIGAL, S.; MASUD, A.; KAPANIA, R.K. A survey of recent shell finite elemens. Int. J. Numer. Meth. Eng, v. 47, p. 101-127, 2000. 